\title{
On the Predictability of Emerging Market Sovereign Credit Spreads*
}

\author{
Alena Audzeyeva ${ }^{\dagger}$ \\ Keele Management School, Keele University \\ ANA-MARIA FUERTES ${ }^{\ddagger}$ \\ Cass Business School, City University of London
}

July 30,2018

\begin{abstract}
This paper examines the quarter-ahead out-of-sample predictability of Brazil, Mexico, the Philippines and Turkey credit spreads before and after the Lehman Brothers' default. A model based on the country-specific credit spread curve factors predicts no better than the random walk and slope regression benchmarks. Model extensions with the global yield curve factors and with both global and domestic uncertainty indicators notably outperform both benchmarks postLehman. The finding that bond prices better reflect fundamental information after the Lehman Brothers' failure indicates that this landmark of the recent global financial crisis had wake-up call effects on emerging market bond investors.
\end{abstract}

KEYwORDs: Sovereign credit spreads; Emerging Markets; Out-of-sample predictability; Term structure; Macroeconomic uncertainty.

JEL Classifications: F34; F15; F17.

\footnotetext{
${ }^{*}$ Correspondence to: A.-M. Fuertes, Faculty of Finance, Cass Business School, City, University of London, 106 Bunhill Row, London EC1Y 8TZ.

${ }^{\dagger}$ Email: a.audzeyeva@keele.ac.uk

${ }_{\ddagger}^{\ddagger}$ Email: a.fuertes@city.ac.uk
} 


\section{Introduction}

Little is known about the out-of-sample, or real-time, predictability of sovereign credit spreads in markets where investors are non-trivially exposed to default risk. Beyond academia, filling this vacuum is important for several reasons. Accurate predictions of emerging market sovereign credit spreads at various maturities are essential for pricing emerging market assets and derivatives, and for international portfolio management. Understanding how domestic and global factors affect future international borrowing costs enables emerging market borrowers to develop better informed economic policies. Due to the systemic importance of the emerging sovereign debt market, the construction of predictive models for emerging credit spreads is relevant for financial market regulators. This is borne out, for instance, by the fact that the defaults of several Latin American and Asian governments (besides Russia) during the 1990s and 2000s triggered global market turmoil. Moreover, the stock of tradable emerging market debt has grown by $17 \%$ per annum since 2002 reaching 11.7 trillion U.S. dollars in 2011 (Bank of America Merrill Lynch, 2012). This fast growth is partly because emerging market bonds attracted large portfolio capital flows due to both their post-crisis relatively favorable risk-return profile and the ultra low interest rates in advanced economies.

This paper contributes to the sparse literature on emerging sovereign bond yield prediction with a comprehensive out-of-sample (OOS) predictive analysis. The aim of this forecasting exercise is to examine two theoretically-motivated hypotheses that have not been tested in the emerging market context as yet. Hypothesis 1 states that the current emergingmarket credit spread curve alone is a sufficient statistic to predict future credit spreads. This hypothesis is motivated by the rational expectations theory of the term structure of interest rates of Sargent (1972) and Roll (1970). The Roll-Sargent theory, which builds on the seminal contributions of Hicks (1939), Lutz (1940) and Muth (1961), contends that whatever 
expectations mechanism is at work about future interest rates, it exploits all the available information. Thus motivated, our paper is the first to test in the emerging-market debt context the hypothesis that the spread curve contains all relevant information for predicting future spreads because it efficiently embeds rational expectations about future spreads. ${ }^{1}$

Thus we begin by constructing OOS forecasts from a parsimonious model that exploits the information content of the current credit spread curve alone; namely, the predictors are the current spread level, slope and curvature factors. To test Hypothesis 1, we deploy a hierarchical modeling approach by which the baseline predictive regression is gradually augmented with different types of global and country-specific macroeconomic predictors. As a by-product, the test can uncover macroeconomic variables that enhance the spreadcurve-based predictions. In this regard, our aim is to advance the current knowledge on the predictability of emerging-market credit spreads which has implications for their modeling.

We further conjecture that emerging market sovereign bond spreads became more aligned with global/domestic fundamentals post-Lehman (Hypothesis 2). This second hypothesis is inspired by the notion of "wake-up call" effects in financial markets as originally put forward by Goldstein et al. (2000) and Bekaert et al. (2011). A wake-up call theory is proposed by Ahnert and Bertsch (2015) using global coordination games. This theory predicts that in normal (or calm) market conditions investors have weak incentives to acquire costly fundamental information about a market; consequently, the market prices may not fully reflect fundamentals. However, a crisis event in another market induces investors to acquire fundamental information about the first market even if they perceive the two markets as unrelated to each other. Following a branch of the empirical finance literature, we focus attention on the collapse of Lehman Brothers in September 2008 given that this event constitutes an

\footnotetext{
${ }^{1}$ Akin to the one-to-one relationship that exists between yields on pure discount bonds and current forward interest rates for riskless bonds, credit spreads on defaultable bonds are linked to current forward spreads.
} 
important landmark of the late 2000s global financial crisis (see e.g., Baskaya et al., 2017; Ongena et al., 2015; Boyer, 2014). As the analysis in Eichengreen et al. (2012) highlights, it was a salient event that signaled to investors the imminence of a global financial crisis.

Our analysis is based on July 1, 2003 to December 31, 2015 data for four geographically dispersed and relatively mature emerging markets: Brazil, Mexico (Latin America), the Philippines (Asia) and Turkey (Eastern Europe). All four borrowers have entered the J.P. Morgan EMBI+ sovereign emerging market bond index - a market benchmark for large, frequently-traded US\$ denominated bond issues - since the early 2000s. While the index is dominated by Latin American sovereigns, Turkey and the Philippines are among a handful of borrowers from other regions that still enter the index at the end of our sample period. Also, from a practical perspective (i.e., for credit spread curve estimation purposes) the size of the Eurobond markets in these four sovereigns affords a relatively large cross-section of bonds throughout the sample period. The available cross-sections of bonds for other emerging markets are much smaller, particularly, in the early part of the sample.

Among the selected countries, Brazil, Mexico and Turkey are large emerging market economies and members of the G20 ("Group of Twenty") forum; in addition, Brazil is a BRICS country. Albeit the Philippines is a relatively small economy, not typically regarded among major emerging markets, it is nevertheless identified by Goldman Sachs as a N11 ("Next Eleven") country alongside Mexico and Turkey. The N11 group consists of emerging market economies that have been predicted to follow the footsteps of the BRICS countries in rivaling major developed economies (Goldman Sachs, 2007).

For each sovereign borrower, we collect at the weekly frequency cross-sections of bond prices and use them to estimate the latent factors of the credit spread curve using the Nelson and Siegel (1987) approach. Given the size of the cross-sections available, the parsimony of 
this approach is important to preserve degrees of freedom and achieve as much accuracy as possible in the factor extraction. We test Hypothesis 1 and Hypothesis 2 using OOS predictive ability tests for the credit spread. ${ }^{2}$ The length in time into the future of the forecasts is one quarter; namely, a $h=13$ week horizon in the context of our sampling frequency.

We find pervasive evidence that the emerging-market credit spread curve is not a sufficient statistic for OOS prediction of the quarter-ahead spread, against Hypothesis 1, as the baseline model forecasts are no better than those from the random walk and credit-slope benchmarks. Adding the global riskless yield curve information reduces significantly the model's predictive errors. The spread curve factors and the global riskless yield curve factors together with the volatility of the riskless short-term interest rate make a better predictive model that is able to beat the benchmarks for both short- and long-term bonds. Domestic fundamentals further enhance the model predictive ability across the bond maturity spectrum. Another novel finding is that indicators of macroeconomic uncertainty, namely, the volatility of the U.S. short-term interest rate, the volatility of the emerging-market sovereign trade balance and terms-of-trade growth are useful predictors of the emerging-market spread. These results provide insights for refining extant structural and reduced-form models of emerging-market sovereign debt (Gibson and Sundaresan, 2005; Duffie et al., 2003; Pan and Singleton, 2008).

Comparing two periods of equal 5-year length surrounding the collapse of Lehman Brothers, we find evidence consistent with Hypothesis 2 (the "wake-up call" effect). The predictive ability of most global and domestic macroeconomic indicators becomes stronger in the 5year period following this salient event which suggests that credit spreads became then more closely aligned with the fundamentals. Extending the post-Lehman period with two more

\footnotetext{
${ }^{2}$ Since credit spreads reflect not only default and recovery assessments but also market liquidity conditions and the investors' ability to diversify credit risk among other factors, changes in credit spread forecasts do not necessarily translate one-for-one into changes in expectations about default and recovery rates. For further discussion, see e.g. Hartelius et al. (2008) and Longstaff et al. (2011) for sovereign emerging market debt and Amato and Remolona (2003) and Huang and Huang (2012) for corporate debt in mature markets.
} 
years, we find weaker predictive ability for all models entertained, particularly, for the longterm bonds. We interpret this evidence as suggesting that bond prices gradually begin to show divergence from the fundamentals as the Lehman Brothers collapse fades away in investors memory. This result confirms the temporary nature of wake-up call effects in financial markets; namely, as time passes and market stability is regained after a distress event, investors' attention to fundamentals begins to subside, reverting to the pre-event state.

Related Literature. There are only two emerging market debt studies that are concerned with OOS predictability, to our best knowledge. Sueppel (2005) predicts the cointegration path of the spread on the Merril Lynch Emerging Market Bond index. Hilscher and Nosbusch (2010) construct a hazard model for forecasting the sovereign's default probability using the J.P. Morgan Emerging Markets Bond Index Global index $;^{3}$ they use the default probability forecasts as inputs to construct hazard-model-implied spreads. Our paper distinguishes itself from these two studies in various aspects. First, the target variables differ. We seek to predict an observable variable, the sovereign credit spread, at a quarter-ahead horizon whereas Sueppel (2005) targets the long-run equilibrium path of the spread which is latent. Unlike Hilscher and Nosbusch (2010) who target the default component of the spread, we predict the entire spread that comprises a default-risk related component and a non-default related risk premium; the latter is sizeable and non-negligible (see, e.g., Longstaff et al., 2011). Second, our predictability analysis is based on disaggregated data for bonds of short and long maturities instead of relying on an index (pooling bonds of different maturities) as proxy for a country's debt portfolio. Finally, these two OOS predictive studies are not concerned with the term structure; namely, their candidate set of predictors includes neither

\footnotetext{
${ }^{3}$ Focusing on the J.P. Morgan Emerging Market Bond Index as debt portfolio, Comelli (2012) estimates a model of emerging-market sovereign credit spreads based on credit risk ratings and global factors such as the VIX volatility index, and U.S. interest rates, but they do not assess the OOS predictability of spreads.
} 
the current sovereign credit spread curve nor the global riskless yield curve.

A vast empirical literature on riskless debt documents that level, slope and curvature of the yield curve contain useful information about future yields (see e.g., Fama and Bliss, 1987, Campbell and Shiller, 1991, and Diebold and Li, 2006). However, more recent studies provide evidence suggesting that the yield curve may not be completely capturing all the relevant information for predicting future yields; see e.g., Ang and Piazzesi (2003), Moench (2008), and Ludvigson and $\mathrm{Ng}$ (2009) for studies of riskless yields and Krishnan et al. (2010) and Thomson et al. (2006) for studies of corporate credit spreads in advanced economies. Our study revisits the latter question, encapsulated in Hypothesis 1, in the context of emerging sovereign credit spreads and from the novel perspective of OOS predictability tests.

The present study is related to empirical papers that assess the determinants of emergingmarket sovereign credit spreads. The established wisdom is that both global factors (e.g., Uribe and Yue, 2006; Hartelius et al., 2008; Longstaff et al., 2011) and domestic macroeconomic indicators (e.g., Min, 1998; Ferrucci, 2003; Baldacci et al., 2008) matter. However, good in-sample model fit and significance of explanatory variables from standard tests does not necessarily translate into predictive ability in real time.

Finally, our paper is in agreement with a literature that has adduced evidence of "wake-up calls" in sovereign debt markets. In the context of Eurozone countries, Caceres et al. (2010), Mink and Haan (2013) and Beirne and Fratzscher (2013) show that, in sharp contrast with the pre-crisis period, markets changed the pricing model to one driven by macroeconomic fundamentals and international risk in the aftermath of the crisis. Our paper distinguishes itself from these studies in that it sheds light on the notion of wake-up calls from the novel lens of OOS predictability tests and in the context of emerging debt markets.

The paper proceeds as follows. Section 2 outlines the predictive models while Section 3 
describes the data. Section 4 discusses the empirical findings. Section 5 concludes the paper.

\section{Methodology}

\subsection{Emerging market zero-coupon credit spreads}

The time $t$ price of a zero-coupon bond that pays $\$ 1$ at $t+\tau$ obeys the relation

$$
p_{i, t}(\tau)=e^{-y_{i, t}(\tau) \tau}
$$

where $i$ denotes the sovereign bond issuer, and $y_{i, t}(\tau)$ is the yield to maturity $\tau$. The target variable in our predictability analysis is the emerging market zero-coupon bond yield spread

$$
s_{i, t}(\tau) \equiv y_{i, t}(\tau)-y_{f, t}(\tau)
$$

where $y_{f, t}(\tau)$ is the time $t$ yield on a U.S. Treasury zero-coupon bond. We extract at the weekly frequency the unsmoothed yields on zero-coupon riskless bonds by applying the Fama and Bliss (1987) methodology to cross-sections of market prices of U.S. Treasuries. ${ }^{4}$ The unsmoothed Fama-Bliss yields price U.S. Treasuries exactly (see Diebold and Li, 2006). Next we fit the Nelson-Siegel-Svensson decomposition to those unsmoothed Fama-Bliss yields by Nonlinear Least Squares (NLS) to obtain the smoothed yields on zero-coupon riskless bonds which are denoted $y_{f, t}(\tau)$ in $(2)$. The Nelson-Siegel-Svensson equation enables superior riskless bond yield estimation accuracy relative to simpler representations (see Svensson, 1994). With these zero-coupon riskless bond yields in hand, we can construct the corresponding emerging-market credit spreads on zero-coupon bonds, denoted $s_{i, t}(\tau)$, as follows.

\footnotetext{
${ }^{4}$ We thank Robert Bliss for sharing his software and data files.
} 
We adopt the parsimonious Nelson and Siegel (1987) decomposition for the spread on the (zero-coupon) maturity $\tau$ bond of the emerging-market sovereign $i$

$$
s_{i, t}(\tau)=\beta_{i 0, t}+\beta_{i 1, t}\left(\frac{1-e^{-\lambda_{i, t} \tau}}{\lambda_{i, t} \tau}\right)+\beta_{i 2, t}\left(\frac{1-e^{-\lambda_{i, t} \tau}}{\lambda_{i, t} \tau}-e^{-\lambda_{i, t} \tau}\right)
$$

where $t=1,2, \ldots, T$ are sample weeks, and the vector $\left(\beta_{i 0, t}, \beta_{i 1, t}, \beta_{i 2, t}\right)^{\prime}$ collects the level, slope and curvature factors, respectively. We extract these latent factors by NLS minimization of the distance between the cross-section of observed coupon-paying emerging market bond prices and the corresponding fitted bond prices from Eqs. (1)-(3) with exponential decay parameter fixed at $\lambda_{i, t}=0.7308$ (annualized yields), as in Diebold and Li (2006). Then with the weekly spread factors in hand, $\hat{\beta}_{i 0, t}, \hat{\beta}_{i 1, t}, \hat{\beta}_{i 2, t}, t=1, \ldots, T$, we can construct weekly zero-coupon emerging market bond spreads for any maturity, $s_{i, t}(\tau)$, using Eq. (3).

\subsection{Hierarchical predictive regressions}

Following Diebold and Li (2006) and Krishnan et al. (2010) in the riskless debt and risky corporate debt contexts, respectively, we construct baseline forecasts for the $h$-week-ahead spread as forward projections of the current spread curve using the predictive equation

$$
s_{i, t+h}(\tau)=\alpha_{i}+\gamma_{i 0} \hat{\beta}_{i 0, t}+\gamma_{i 1} \hat{\beta}_{i 1, t}+\gamma_{i 2} \hat{\beta}_{i 2, t}+\varepsilon_{i, t+h}, t=1,2, . ., T
$$

The parameters $\alpha_{i}$ and $\gamma_{i j}, j=0,1,2$, are estimated by OLS using the weekly time-series of emerging market spreads and spread curve factors. ${ }^{5}$ In a hierarchical regression approach,

\footnotetext{
${ }^{5}$ Diebold and Li (2006) employ instead a two-step forecasting method by, first, fitting autoregressive models (by OLS) to the estimated weekly factors to capture persistence, and then using the corresponding projections, $\hat{\beta}_{i j, t+h}=f\left(\hat{\beta}_{i j, t}\right), j=0,1,2$ as predictive variables in Eq. (4).
} 
we gradually add global macroeconomic factors, $\boldsymbol{G}_{t}$, and formulate the predictive model

$$
s_{i, t+h}(\tau)=\alpha_{i}+\gamma_{i 0} \hat{\beta}_{i 0, t}+\gamma_{i 1} \hat{\beta}_{i 0, t}+\gamma_{i 2} \hat{\beta}_{i 2, t}+\boldsymbol{\theta}_{i}^{G} \boldsymbol{G}_{t}+\varepsilon_{i, t+h}
$$

and emerging-market specific macroeconomic factors, $\boldsymbol{E} \boldsymbol{M}_{i, t}$, leading to the predictive model

$$
s_{i, t+h}(\tau)=\alpha_{i}+\gamma_{i 0} \hat{\beta}_{i 0, t}+\gamma_{i 1} \hat{\beta}_{i 0, t}+\gamma_{i 2} \hat{\beta}_{i 2, t}+\boldsymbol{\theta}_{i}^{G} \boldsymbol{G}_{t}+\boldsymbol{\theta}_{i}^{E M} \boldsymbol{E} \boldsymbol{M}_{i, t}+\varepsilon_{i, t+h},
$$

The predictive horizon is one-quarter-ahead ( $h=13$ weeks). We discuss the candidates for global predictors, $\boldsymbol{G}_{t}$, and domestic predictors, $\boldsymbol{E} \boldsymbol{M}_{i, t}$, in the next section.

For the OOS predictability analysis, we split the $T$ weekly data points available per period into an estimation window $\left(T_{0}=2 / 3 T\right.$ weeks $)$ and a holdout or evaluation window $\left(T_{1}=1 / 3 T\right.$ weeks). The predictions are obtained recursively. The first estimation window spans week $t=1$ up to week $t=T_{0}$ and enables a first $h$-week-ahead prediction $\hat{s}_{i, t+h \mid t}(\tau)$. The window spanning weeks $t=1$ to $t=T_{0}+1$ enables a second prediction and so forth.

\subsection{Evaluation of predictive ability}

We utilize the mean square error (MSE) statistic, which captures the expected value of the squared error loss or quadratic loss, to measure the quality of the quarter-ahead OOS forecasts $\hat{s}_{i, t}(\tau)$. Significance is assessed through the Clark and West (2007) one-sided MSEadjusted $t$-test. The relevant question in our hierarchical modeling approach is: Does model B produce superior OOS forecasts than a simpler (nested) model A. Under $H_{0}$, model $\mathrm{A}$ is assumed to generate the data and therefore model $\mathrm{B}$ requires estimating unnecessary parameters which introduces noise in the $M S E_{B}$. Hence, the expected value of the differential $M S E_{A}-M S E_{B}$ is negative under $H_{0}$; the adjustment of the Clark-West 
test statistic is meant to account for this noise and the test hypotheses are formulated as $H_{0}: M S E_{A} \leq M S E_{B}$ against $H_{A}: M S E_{A}>M S E_{B}$. Thus, a test rejection indicates that the augmented model B produces more accurate OOS forecasts than the nested model A.

A second set of OOS predictability tests is aimed at benchmarking. The idea is to assess whether our predictive regressions, Eqs. (4)-(6), are able to beat those models employed as benchmarks in the literature. Given the stylized persistence of credit spreads, a widely-used benchmark is the random walk (RW) model $s_{i, t+h \mid t}^{R W}(\tau)=s_{i, t}(\tau)+\varepsilon_{i, t+h}$. Another benchmark in the literature is a time-series OLS regression of the future credit spread change on the current credit spread slope, $s_{i, t+h}(\tau)-s_{i, t}(\tau)=c_{i}+d_{i}\left(s_{i, t}(\tau)-s_{i, t}(2)\right)+\varepsilon_{i, t+h}$, where $s_{i, t}(2)$ denotes the 2-year credit spread; see, for instance, Cochrane and Piazzesi (2005) and Diebold and $\mathrm{Li}$ (2006). Since the benchmarking involves comparing non-nested models, we employ the Diebold and Mariano (1995) two-sided $t$-test which hypothesizes $H_{0}: M S E_{b}-M S E_{j}=0$ against $H_{A}: M S E_{b}-M S E_{j} \neq 0$, with the subscripts $j$ and $b$ denoting the candidate predictive model and the benchmark at hand, respectively. Both sets of OOS predictive ability tests are adjusted for autocorrelation in the weekly OOS forecast error sequence.

\section{Credit Spreads and Predictors: Data Description}

\subsection{Bond market price data and preliminary analysis}

At the first stage, the modeling and forecasting exercise is carried out separately over two periods of approximately 5-year length surrounding the Lehman Brothers' default. The first period is July 1, 2003 to September 14, 2008 (pre-Lehman; 268 weeks). Excluding the anomalous weeks immediately following the Lehman Brothers' bankruptcy, the second period is December 1, 2008 to December 31, 2013 (post-Lehman; 263 weeks). At the second 
stage, we extend the post-Lehman period by two years to December 31, 2015. The data used for the riskless zero-coupon bond yield extraction and corresponding term-structure curve fitting are midweek bid-ask average price quotes for U.S. Treasury bonds obtained from the Center for Research in Security Prices. Over 100 prices are available per week.

We establish various bond eligibility criteria towards achieving reliable term structure estimation. The first requirement is the availability on each weekly observation point of market prices for at least six Eurobond issues across a range of maturities (from 1 to 32 years). The minimum amount at issue is $\$ 500$ million to mitigate illiquidity. Since very few emerging-market Eurobonds with maturity below 3 years or above 20 years are available on a trading day, we focus the analysis on 3- to 20-year maturities. The pool of eligible bonds per country is further filtered to retain only plain-vanilla bond issues, with fixed regular coupon payments and without collateral, sink funds or other special contractual aspects. ${ }^{6}$

The primary data source is Bloomberg but we use Datastream as supplementary source to fulfill our requirement of at least 6 market bond prices observed on any given week (14\% of our bond price series are from Datastream). The week-by-week spread curve fitting is finally based on cross-sections of between 9 and 19 (6 and 17) midweek bid-ask average prices for U.S. dollar denominated Eurobonds issued by Brazil, Mexico and Turkey (the Philippines).

The empirical distribution of the bond pricing error (i.e., observed minus fitted price) for a $\$ 100$ bond has a mean value of less than 2 cents for U.S. Treasuries and between 1 and 8 cents for emerging market bonds on average across maturities and sample weeks. The dispersion of the pricing errors, given by the standard deviation, is 27 cents for the U.S. market, and between 76 and 112 cents for emerging markets. These statistics for the bond pricing errors compare well with those reported in similar studies of speculative and low

\footnotetext{
${ }^{6}$ Using data on sovereign CDS spread contracts is problematic in the present emerging-market context because of illiquidity at both short and long maturities. Ammer and Cai (2007) show that for many emerging sovereigns the price discovery occurs in the bond market which they ascribe to the lesser CDS market liquidity.
} 
investment-grade bonds such as Elton et al. (2001) and Krishnan et al. (2010).

Figure 1 shows the weekly emerging-market spread curves for 3- to 20-year maturity bonds. To preserve space, hereafter the discussion is confined to a short (5-year) maturity and a long (15-year) maturity. ${ }^{7}$ Various stylized facts are confirmed by the summary statistics for the weekly credit spreads and spread curve factors shown in Table 1.

\section{[Insert Figure 1 and Table 1 around here]}

First, the credit spread curves exhibit time heterogeneity. The common time-variation reflects the global business cycle. For instance, all four spread curves decline during the 20032006 period of favorable global financial conditions and ample liquidity. This is followed by a moderate rise in spreads during the turbulent 2007-2008 period. In September 2008 (Lehman Brothers' bankruptcy), the curves shift upwards sharply. Moreover, the curves are mainly upward-sloping but the slope somewhat lessens post-Lehman reflecting the start of a global recovery. Consistent with a slow improvement in global fundamentals and relatively stable country-specific economic conditions, the time variation in the credit curve level $\hat{\beta}_{0, t}$ and slope $\hat{\beta}_{1, t}$, captured by their standard deviation also lessens post-Lehman (Table 1). The first-order autocorrelation coefficient of the credit spread confirms its stylized persistence. ${ }^{8}$

Second, there is also heterogeneity across the four sovereign credit spread curves which reflects differences in the fundamentals underlying their debt repayment ability. This is especially evident at the beginning of the sample period in line with the different ratings assigned by the S\&P's agency: low speculative grade B for Brazil and Turkey, higher speculative grade BB for the Philippines, and investment grade BBB for Mexico.

While all four economies benefited from favorable global economic conditions reflected in

\footnotetext{
${ }^{7}$ We also analyzed the predictability of emerging market sovereign spreads for 3-, 10-, and 20-year maturity bonds. The findings are broadly similar to those discussed in the paper; details are available upon request.

${ }^{8}$ Credit spreads are theoretically conceptualized as realizations from persistent but stationary processes.
} 
a considerable downward shift in credit spread curves in the mid 2000s, increased differences in their debt repayment ability are revealed post-Lehman through substantial cross-section heterogeneity of credit spread curves. In particular, relatively small fluctuations in the credit spread curves of Mexico and the Philippines are aligned with a stable investment grade BBB rating for Mexico and an upgrade from speculative grade BB to investment grade BBB rating on May 2, 2013 for the Philippines. Both countries remain investment grade rated with stable or positive rating outlooks until the end of the sample period.

The credit spread curves of Brazil and Turkey fluctuate more. The S\&P's agency upgraded the rating for Turkey to BB on August 17, 2004 but between April 3, 2008 and February 7, 2014 it issued a series of negative rating outlooks that signaled a heightened downgrade risk; the credit spread curve of Turkey exhibits several jumps during this period. Brazil's rating improved notably pre-Lehman from a low speculative grade B to BB on September 17, 2004 and to investment grade BBB on April 30, 2008. However, this trend reversed on June 6, 2013 when S\&P's issued the first of various consecutive negative rating outlooks for Brazil that ended up in a downgrade to speculative grade BB on September 9, 2015; accordingly, the credit spread curves of Brazil shift upwards during this period.

\subsection{Global macroeconomic predictors}

Our hierarchical regression approach starts by constructing OOS quarter-ahead spread predictions from the baseline credit spread curve model, Eq. (4). Next, we expand the model with various macroeconomic variables and assess the OOS predictability gains.

Among the global macroeconomic variables, the first natural candidates are the level,

slope, and curvature factors $\left(\beta_{f 0, t}, \beta_{f 1, t}, \beta_{f 2, t}\right)^{\prime}$ that jointly summarize the information con- 
tent of the global riskless yield curve. ${ }^{9}$ The motivation is twofold. First, through its impact on domestic business conditions, the global interest rate influences the emerging economy's future ability to repay external debt. The current global riskless yield curve is thus likely to convey information about the future default-risk related component of the emerging market sovereign spread. ${ }^{10}$ Empirically, it has been shown that U.S. interest rate shocks are responsible for about $20 \%$ of fluctuations in an emerging economy's aggregate activity, and the transmission mechanism occurs mainly through the country's credit spread that determines the borrowing cost that the country faces in international markets (Uribe and Yue, 2006).

Second, the global interest rate influences global liquidity conditions and investors' risk appetite which, in turn, affect the demand for emerging-market sovereign bonds and therefore, the (non-default) emerging-market risk premium component of the spread (Longstaff et al., 2011). In other words, the U.S. Treasury bond yield reflects the Fed's monetary policy path which influences the capital re-allocation among asset classes globally and the net capital flows to emerging markets. For instance, an expansionary U.S. monetary policy together with a decrease in investors' risk aversion can fuel the "search for yield" which leads to surges in the global demand for emerging market bonds and lower spreads; tighter monetary conditions in major economies and a drying up of global liquidity can reverse the capital flows and increase the spreads (Hartelius et al., 2008; Ciarlone et al., 2009).

Our next candidate predictor is the U.S. short-term interest rate volatility, denoted $\sigma_{f, t}^{\text {short }}$ and measured at the weekly frequency (on each week $t=1,2 \ldots, T$ of the sample period) as the standard deviation of the weekly 1-year U.S. Treasury bond yield over the most recent

\footnotetext{
${ }^{9}$ Following Diebold and Li (2006), we fit the Nelson and Siegel (1987) decomposition to the unsmoothed Fama-Bliss yields on zero-coupon U.S. Treasury bonds to obtain the three latent factors.

${ }^{10}$ In the neoclassical growth model of Uribe and Yue (2006), a positive U.S. interest rate shock contracts the emerging economy's output and investment. The small open economy model of Neumeyer and Perri (2005) contends that shocks to the U.S. interest rate influence emerging-market business conditions. The structural sovereign debt model of Gibson and Sundaresan (2005) predicts a counter-cyclical relationship between the global business cycle, which is signaled by the global interest rate, and the credit spread.
} 
10-week window. Greater uncertainty about the monetary policy of major economies (global business conditions) as signaled by higher U.S. short-term interest rate volatility, poses a challenge for international investors regarding financial risk allocation decisions (e.g., Hartelius et al., 2008; Arora and Cerisola, 2001). Higher U.S. short-term interest rate volatility also implies greater uncertainty about global liquidity which is likely to widen the emerging market spread. Figure A1 (Panel I) in the on-line Addendum visually illustrates this point through time-series graphs of the weekly 5 -year credit spreads, $s_{i, t}(5), i=\{$ Mexico, Turkey $\}$, alongside the 13 -week-lagged U.S. short-term interest rate volatility, $\sigma_{f, t-13}^{\text {short }}$. The post-Lehman sample correlation coefficient between the two variables is large and positive ranging across the four countries between 0.60 and $0.80(0.62$ and 0.79$)$ for the 5 - (15-) year credit spreads. ${ }^{11}$

The global macroeconomic variables are added to the baseline model in a two-step hierarchical fashion leading to the re-specification of Eq. (5) as model $G 1$ with the global predictors $\boldsymbol{G}_{t} \equiv\left(\beta_{f 0, t}, \beta_{f 1, t}, \beta_{f 2, t}\right)^{\prime}$, and model $G 2$ with $\boldsymbol{G}_{t} \equiv\left(\beta_{f 0, t}, \beta_{f 1, t}, \beta_{f 2, t} ; \sigma_{f, t}^{s h o r t}\right)^{\prime}$. The sample distribution of the global macroeconomic variables is summarized in Table 1.

\subsection{Domestic macroeconomic predictors}

Extant business cycle theory and evidence suggest that an emerging-market sovereign's external sector conveys information about its economic conditions which, in turn, drives future credit spreads. The sovereign's trade balance signals its ability to generate funds in hard currencies for servicing external debt and the volatility of trade balance signals uncertainty thereof. The small-open-economy model of Neumeyer and Perri (2005) decomposes the real interest rate into two components, international rate and country risk, and suggests that net exports are more strongly counter-cyclical in emerging markets than in developed ones.

\footnotetext{
${ }^{11}$ The counterpart correlations pre-Lehman are much lower ranging across countries between -0.32 and $-0.13(-0.22$ and -0.05$)$ for the $5-(15-)$ year bonds.
} 
A greater trade balance in emerging economies has been shown to be linked with output, consumption and investment contraction (Aguiar and Gopinath, 2007; Neumeyer and Perri, 2005). In the real business cycle model for an emerging economy of Aguiar and Gopinath (2007), trend shocks to productivity growth are the key driver of economic growth, and the volatility of trade balance signals the relative weight of trend versus temporary shocks. This aligns well with the finding that trend shocks to productivity growth can quantitatively match the frequency of defaults in emerging economies (Aguiar and Gopinath, 2006).

Thus motivated, we assess the OOS predictive ability of the trade balance $\left(T B_{i, t}\right)$ defined as the month $t$ exports minus imports over GDP in US\$, and the volatility of trade balance $\left(\sigma_{i, t}^{T B}\right)$ given by the standard deviation of $T B_{i, t}$ over the most recent 6 -month window. The data are from Datastream and weekly $T B_{i, t}$ and $\sigma_{i, t}^{T B}$ are obtained by interpolation. The link between credit spreads, $s_{i, t}(\tau)$, and lagged trade balance volatility, $\sigma_{i, t-13}^{T B}$, can be informally gleaned from the time-series plots in Figure A1 (Panel II) of the on-line Addendum.

It is also known that terms-of-trade shocks affect economic activity mainly through fluctuations in the price of energy and other commodities. In the context of emerging economies, the effect is amplified by specialization in commodity exports, dependence on imported capital goods, and limited access to global financial markets (Chen and Rogoff, 2003; Mendoza, 1995; IMF, 1991). Previous research has linked current terms-of trade-growth and future sovereign default risk (Bulow and Rogoff, 1989; Hilscher and Nosbusch, 2010).

The savings-under-uncertainty neoclassical model of Mendoza (1997) predicts a positive link between terms-of-trade changes and economic growth, and implies also that high termsof-trade growth variability can impair economic growth and reduce social welfare. Extant evidence suggests that not only the terms-of-trade growth but also its volatility are significant determinants of future emerging market sovereign default risk (Hilscher and Nosbusch, 2010). 
These considerations motivate us to examine the forecasting ability of terms-of-trade growth $\left(\Delta T T_{i, t}\right)$ and volatility of terms-of-trade growth $\left(\sigma_{i, t}^{\Delta T T}\right) . \Delta T T_{i, t}$ is measured on each sample month $t$ as the annual percentage change in the US\$ price of the country's exports relative to the US\$ price of its imports; $\sigma_{i, t}^{\Delta T T}$ is the standard deviation of $\Delta T T_{i, t}$ over the most recent 6-month window. The data are from Datastream and we also conduct weekly interpolation.

For completeness, we entertain also as predictor the emerging-market financial risk rating (referred to as country rating, CR, for simplicity hereafter) provided by the International Country Risk Guide of the Political Risk Services Group. The CR captures sovereign risks related to the deterioration in various foreign debt related indicators - foreign debt to GDP, foreign debt service to exports, current account to exports, official reserves and exchange rate stability - which have been shown to be contemporaneously linked to the credit spread; see Min (1998) and Eichengreen and Mody (1998) inter alia. Hence, the CR complements the aforesaid external sector variables by signalling the more imminent ability of debt repayment.

The numerical scale of the $\mathrm{CR}$ and, importantly, its regular monthly updating makes it more attractive as candidate predictor than the letter-based credit ratings of the Fitch, Moody's and S\&P's agencies that signal broadly similar information but suffer from staleness. ${ }^{12}$ The CR is employed as country credit risk proxy in IMF research; see, e.g., Luengnaruemitchai and Schadler (2007), Comelli (2012) and Csonto and Ivaschenko (2013). Figure 2 plots the CR and the Credit Rating-Outlook Index (CROI) which is a transformation of the S\&P's credit rating into a numerical scale using the Hartelius et al. (2008) method. ${ }^{13}$ Figure 2 shows that CRs and CROIs co-move strongly but negatively since a higher CR (CROI) signals better (worse) creditworthiness. More importantly, the CROI tends to lag the CR

\footnotetext{
${ }^{12}$ The construction of the CR measure (in a 0-50 scale) is explained in Csonto and Ivaschenko (2013) and http://www.prsgroup.com/about-us/our-two-methodologies/icrg.

${ }^{13}$ Hartelius et al. (2008) propose a non-linear transformation of the S\&P's letter-based credit ratings, with rating modifiers and outlooks, into a 0-50 scale (the CROI) using calibration to bond pricing data.
} 
by roughly four months; the sample correlation between $\mathrm{CR}$ and the 4-month lagged CROI is $-0.68,-0.53,-0.82$, and -0.54 for Brazil, Mexico, the Philippines and Turkey, respectively.

Through a monthly panel regression analysis, Comelli (2012) finds evidence of a significant relation between the credit spread and the one-month lagged CR which leaves some predictive scope for the latter. On the other hand, the literature predominantly finds a contemporaneous monthly relationship between agency's credit ratings and credit spreads (e.g., Hartelius et al., 2008, Jaramillo and Tejada, 2011, and Bussière and Ristiniemi, 2012) which suggests an even shorter-term ability, if any, of the agency's credit ratings to predict the credit spread. However, event-study analyses of the daily spread dynamics do not bear out this predictive scope as they reveal a largely anticipatory response of the spread; namely, most of the action in the credit spread occurs prior to the actual rating event (e.g., González-Rozada and Yeyati, 2008, and Bussière and Ristiniemi, 2012). ${ }^{14}$ Altogether, this evidence supports our choice of the $\mathrm{CR}$ as a candidate predictor over the agency's credit rating, particularly, given the forecasting horizon (3 months) of interest in the paper.

[Insert Figure 2 around here]

We built our predictive models in a hierarchical fashion as follows. Adding the CR variable to the model at hand, $G 2$, we obtain the model called $G E M_{1}$. Next we add the trade balance to obtain $G E M_{2}$, and the volatility of trade balance to obtain $G E M_{3}$. Finally, model $G E M_{4}$ includes also terms-of-trade growth, and $G E M_{5}$ adds the volatility of terms-oftrade growth. Summary statistics for the country-specific external sector variables and CR are provided in Table 1. The full list of specifications is shown in Table 2.

[Insert Table 2 around here]

\footnotetext{
${ }^{14} \mathrm{~A}$ parallel literature utilizes binary response models to assess the ability of the agency's credit ratings to anticipate financial distress events (e.g., debt crises). The predictive information content of ratings, if any, is very low versus that of fundamentals (see e.g., Reinhart, 2002 and Bussière and Ristiniemi, 2012).
} 


\section{Empirical results}

\subsection{Predictive ability in 5-year pre- and post-Lehman periods}

The baseline credit spread factor model and the two extensions with global variables, models G1 and G2, are compared in Table 3. Using expanding estimation windows, we construct 92 quarter-ahead OOS spread forecasts in the 5-year pre-Lehman period; the first forecast (based on a window of 163 weeks) is for November 28, 2006 and the last one for September 9, 2008. In the 5-year post-Lehman period, the number of OOS forecasts is 90; the first forecast (160-week window) is for March 27, 2012 and the last one for December 31, 2013.

Global macroeconomic variables. The information content in the global riskless yield curve enhances the OOS predictive ability as borne out by the small root mean square error ratio of model $G 1$ relative to the baseline model (i.e., $R M S E_{G 1} / R M S E_{b a s e}<1$ ) reported in Table 3. This finding represents evidence against Hypothesis 1 that the credit spread curve is a sufficient statistic to predict the future spread. On average across countries, the reduction in forecast errors afforded by the global riskless yield curve $\left(1-R M S E_{G 1} / R M S E_{b a s e}\right)$ is $-0.1 \%$ and $2.6 \%$ pre-Lehman and a remarkably larger $12.0 \%$ and $11.5 \%$ post-Lehman for the 5- and 15-year bonds, respectively. The one exception is Brazil pre-Lehman where augmenting the model with the riskless yield curve factors adds noise to the predictions $\left(R M S E_{G 1} / R M S E_{b a s e}>1\right)$. Towards explaining this contrasting finding for Brazil, we notice a distinct sharp fall in its credit spreads pre-Lehman. Helped by favorable global market conditions and investors' search for yield, the dramatic improvement in Brazil's credit rating from B in 2003 to BBB in 2008 may have induced over-confident sentiment towards Brazil that decoupled its spreads from the levels consistent with the global interest rate.

[Insert Table 3 around here] 
Further adding the volatility of the U.S. short-term interest rate shrinks the forecast errors $\left(1-R M S E_{G 2} / R M S E_{G 1}>0\right)$ on average across countries by $0.4 \%$ and $3.5 \%$ preLehman and by $6.6 \%$ and $5.5 \%$ post-Lehman for the 5 - and 15 -year bonds, respectively. The Clark and West (2007; CW) tests unambiguously confirm that this global macroeconomic uncertainty indicator adds significant predictive content post-Lehman to the credit-spread curve and riskless yield curve across the bond maturity spectrum. This evidence supports Hypothesis 2 on the "wake-up"effect of the Lehman Brothers' collapse.

Next we benchmark the baseline predictive model and its extensions with global macroeconomic indicators (models $G 1$ and $G 2$ ) against the random walk and slope-regression. The results are set up in Table 4 . Reported RMSE ratios below unity indicate that the candidate model gives more accurate forecasts than the benchmark. A significant and positive DieboldMariano $t$-test statistic indicates that the candidate model outperforms the benchmark.

[Insert Table 4 around here]

The baseline model, Eq. (4), almost never beats both benchmarks, neither pre-Lehman nor post-Lehman; exceptions are the 5-year bonds of the Philippines and 5 and 15-year bonds of Turkey post-Lehman when both benchmarks are outperformed by the credit curve model at the 5\% significance level. Exploiting the global riskless yield curve reduces the model G1 forecast errors enough for it to outperform both benchmarks post-Lehman, with some exceptions (Brazil 5 and 15-year bonds, and Mexico 15-year bonds). It is only when the U.S. short-term interest rate volatility is added as predictor that, for all countries and bond maturities, the resulting model $G 2$ beats both benchmarks post-Lehman. In sharp contrast, pre-Lehman models $G 1$ and $G 2$ generally fail to outperform both benchmarks. These findings altogether represent further evidence against Hypothesis 1 about the informativeness of the credit spread curve alone, but provide support for the wake-up call Hypothesis 2. 
As a robustness check, we reformulated the predictive regressions substituting the first three Principal Components (PCs) of the credit spreads and the U.S. Treasury yields, respectively, for the level, slope and curvature of the country credit spread curve and the global riskless yield curve. ${ }^{15}$ The resulting RMSE ratios and significance statistics do not challenge the above findings, and are not reported to preserve space (available upon request).

Domestic macroeconomic variables. Next we assess the predictive content of the CR and external sector variables through our hierarchical regression approach by confronting models GEM1 and G2, models GEM2 and GEM1, and so on. Table 5 reports the results.

\section{[Insert Table 5 around here]}

At both the short- and long-end of the bond maturity spectrum, the country-specific external sector indicators afford significant predictive gains, especially post-Lehman. Most prominently, the information content in the volatility of the trade balance significantly improves the OOS forecasts for short- and long-term maturity bond spreads, particularly postLehman; the only exception is the Philippines. On average across Brazil, Mexico and Turkey, a post-Lehman forecast error reduction $\left(1-R M S E_{G E M 3} / R M S E_{G E M 2}>0\right)$ of $8.5 \%$ and $11.6 \%$ is achieved for the 5- and 15-year credit spreads, respectively. Again post-Lehman only, the information content in the volatility of terms-of-trade growth improves the accuracy of forecasts $\left(1-R M S E_{G E M 5} / R M S E_{G E M 4}>0\right)$ for the Brazil short- and long-term bond spreads and the Mexico short-term bond spreads. These distinctive results for Brazil and Mexico are plausible given that both countries are highly reliant on commodity exports.

The absence of evidence on the predictive role of external trade volatility indicators for the Philippines is not surprising. To begin with, data on its terms-of-trade data is unavailable

\footnotetext{
${ }^{15}$ At weekly frequency, we extract the PCs of credit spreads on zero-coupon bonds of $3,4, \ldots, 20$ year maturity and yields on U.S. zero-coupon bonds of $1,2, \ldots, 20$ year maturity.
} 
for most of the sample period which precludes the study of the predictive models GEM4 and GEM5. The Eurobond market for the Philippines is notably smaller than that of Brazil, Mexico and Turkey, reflecting the much smaller size of this economy. ${ }^{16,17}$ Smaller bond market size is generally associated with higher market frictions such as the cost of trading due to lower trading volumes and lesser liquidity, and also with higher information costs. These sovereign bond market frictions may hinder predictability by obscuring the nexus between the credit spread and past country-specific macroeconomic fundamentals.

The trade balance and terms-of-trade growth exhibit also less predictive ability pre- than post-Lehman, consistent with Hypothesis 2. However, their overall predictive ability is less remarkable than that of the volatility of the trade balance and terms-of-trade growth. The forecast error change afforded by the trade balance level $\left(1-R M S E_{G E M 2} / R M S E_{G E M 1}\right)$ is either positive but statistically insignificant or negative. The information in the level of terms-of-trade growth helps to reduce the forecast error $\left(1-R M S E_{G E M 4} / R M S E_{G E M 3}>0\right)$ for Brazil and Turkey at about 5.1\% altogether but only regarding the 15-year bonds.

The domestic CR predictor stands in contrast with the external sector variables due to its weaker OOS predictive power post-Lehman. The error reduction $\left(1-R M S E_{G E M 1} / R M S E_{G 2}\right)$ is $5.0 \%$ and $6.0 \%$ pre-Lehman versus $-3.7 \%$ and $-0.1 \%$ post-Lehman on average across countries for the 5- and 15-year bonds, respectively. Our rationale for this finding is that the significant predictive content of the CR for credit spreads pre-Lehman indicates that the information it conveys about imminent sovereign debt paying ability is then less quickly

\footnotetext{
${ }^{16}$ Many sovereign emerging Eurobond markets, including new or historically small markets, expanded considerably during 2003-2013. For instance, external financing of new bond issuance measured by the four-year total (in billions US\$) trebled or even became four times larger from $\$ 40.7, \$ 30.3$, and $\$ 19.2$ in 2000-2003 to $\$ 168.9, \$ 119.2$, and $\$ 53.5$ in 2010-2013 for Brazil, Mexico and Turkey, respectively (IMF, 2004, and IMF, 2014). In contrast, the Philippines' new issuance expanded moderately from $\$ 12.9$ to $\$ 18.0$ billion.

${ }^{17}$ For instance, in the 4th quarter of 2013 the size of the Philippines economy by GDP was more than 3-fold smaller than that of Turkey, and 8-fold smaller than Brazil. The respective figures are 2.5, 1.3, 1.0 and 0.3 trillion US $\$$ for Brazil, Mexico, Turkey and the Philippines (Source: Datastream).
} 
impounded into bond prices. The quarter-ahead predictive content of the CR vanishes postLehman, reflecting a dramatic change in the emerging-market bond price discovery process which becomes then more efficient; this evidence is consistent with Hypothesis 2.

Finally, we benchmark the OOS predictions. The results are reported in Table 6 .

\section{[Insert Table 6 around here]}

During the pre-Lehman period, the augmented models with external sector variables and the CR generally fail to outperform the two benchmarks. In sharp contrast, post-Lehman the same models beat the benchmarks for all countries and bond maturities. Overall the findings indicate that credit spreads became more closely aligned with fundamentals post-Lehman.

\subsection{Predictive ability in the extended post-Lehman period}

As the crisis event begins to fade away in investors' memory and the markets regain stability, the incentive to acquire costly country-specific fundamental information begins to wane. To test this transitory wake-up call effects notion, we repeat the predictability analysis in an extended post-Lehman period that includes two further years - ending on December 31, 2015 ( $T=367$ weekly data points). Using the same expanding estimation window approach and maintaining the same ratio of initial estimation window size $\left(T_{1}=2 / 3 T\right)$ and evaluation window size $\left(T_{2}=1 / 3 T\right)$, the first forecast is for July 30, 2013 and the last one for December 29, 2015. Table 7 illustrates the marginal predictive ability of global and domestic variables.

\section{[Insert Table 7 around here]}

The results in Panel A indicate that the global riskless yield curve no longer enhances predictive ability as borne out by a large root mean square error ratio of model $G 1$ relative to the baseline model (i.e., $R M S E_{G 1} / R M S E_{\text {base }}>1$ ), with the exception of the 5-year 
bonds for the Philippines. Nevertheless, the U.S. short-term interest rate volatility remains an important predictor for all countries; the RMSE reduction $\left(1-R M S E_{G 2} / R M S E_{G 1}\right)$ that this global uncertainty indicator delivers is similar across the 5- and 15-year bond maturities and similar to its earlier post-Lehman value. The analysis of domestic predictors in Panel B suggests that the external trade variables remain important but their predictive content in the 7-year post-Lehman period weakens relative to the 5-year post-Lehman period.

The benchmarking analysis summarized in Table 8 also reveals that the predictive ability of both the baseline model and extensions with global and country-specific fundamentals somewhat lessens in the extended post-Lehman period. Specifically, neither the baseline model nor extensions obtained by adding global/domestic predictors are generally able to beat both benchmarks, a finding common across the 5- and 15-year maturity bonds. The deterioration in the models' predictive ability is more pronounced for the long-term maturity bonds. For instance, the RMSE reduction of the baseline model relative to the benchmarks $\left(1-R M S E_{\text {Base }} / R M S E_{\text {Bench }}\right)$ declined on average across countries from $15 \%$ and $12 \%$ postLehman to $12 \%$ and $5 \%$ in the extended post-Lehman period for the 5 - and 15 -year maturity bonds, respectively. This is consistent with the notion of transitory wake-up call effects.

[Insert Table 8 around here]

We observe that the baseline and some augmented models for Brazil and Turkey (albeit only for the 5-year bonds) outperform both benchmarks in the extended post-Lehman period. These two countries have in common that they experienced a downward trend in their creditworthiness in the extended post-Lehman period which may explain why investors' incentives to monitor their fundamentals did not lessen in 2014 and 2015. In particular, the rating assigned to Brazil by S\&P's reversed its long-run upward trend on June 6, 2013 with the issuance of a negative rating outlook leading to several subsequent negative rating changes 
pushing Brazil into the speculative grade rating category. Likewise, Turkey experienced several negative rating outlooks between April 3, 2008 and February 7, 2014.

These findings together with evidence of a weakened overall predictive ability of both domestic sets of predictors, including the country credit spread and country-specific fundamentals, affirm our overall conclusion that emerging bond market investors' attention to fundamentals generally slipped during the extended post-Lehman period. The results also indicate that the U.S. interest rate curve loses predictive ability in this period. ${ }^{18}$

As a robustness check, we reformulated the predictive regressions by dropping the U.S. yield curve factors as they become uninformative in the extended post-Lehman period (see Table 7), and repeated the benchmarking exercise. The resulting RMSE ratios and significance statistics reported in Table A2 of the on-line Addendum confirm our earlier findings.

\section{Conclusions}

This paper contributes to the literature that examines the behavior of emerging-market sovereign credit spreads by providing a comprehensive out-of-sample predictability analysis. The investigation is organized around two novel hypotheses in the context of emerging market debt which have implications for policy-makers and bond investors. Hypothesis 1 states that the current spread curve is a sufficient statistic to predict future spreads. Building on the notion of "wake-up calls" in financial markets, Hypothesis 2 states that the spreads became more closely aligned with fundamentals after the Lehman Brothers' collapse. In order to test these hypotheses, we generate quarter-ahead predictions in pre- and post-Lehman periods for four emerging-market sovereigns with relatively large and liquid bond markets (Brazil,

\footnotetext{
${ }^{18}$ The unprecedented long episode of extremely low U.S. interest rates that followed after the Lehman Brothers' failure may explain why the U.S. yield curve factors become less informative for global investors in the extended post-Lehman period. Therefore, without further specific tests to ascertain the latter we cannot for sure attribute a weaker predictive ability of the U.S. yield curve factors to wake-up call effects.
} 
Mexico, the Philippines and Turkey) using a hierarchical regression approach.

The baseline model that exploits solely the information content in the current credit spread curve is unable to outperform the canonical random walk and slope-regression benchmarks. Adding global and country-specific macroeconomic variables reduces the prediction errors. This evidence refutes Hypothesis 1 and aligns well with extant evidence for riskless debt, questioning the assumptions of many affine term-structure models.

Measures of uncertainty about either the global economic outlook or the borrower's future ability to repay debt convey useful information for future emerging-market credit spreads. Volatility indicators therefore may serve as useful early-warning tools by policy-makers and market participants. Overall we see also significantly greater predictive ability of global and country-specific macroeconomic indicators post-Lehman which, consistent with the wake-up call Hypothesis 2, suggests that the pricing of emerging market bonds became then more closely aligned with fundamentals. However, the evidence in this regard weakens over an extended post-Lehman period which confirms that the wake-up call effects are transitory.

Our findings endorse policies aimed at promoting emerging-market stability by restraining the volatility of U.S. monetary policy. They also promote policies aimed at sustaining long-term growth in emerging economies by stabilizing their net exports and terms-of-trade growth. Such long-term macroeconomic risk management via institutional and policy change is promoted in Gray and Malone (2008). Our findings also endorse the proposition made by Hilscher and Nosbusch (2010), Caballero (2003) and Merton (2005) that sovereign borrowers should consider innovative financial instruments to hedge macroeconomic risk exposures. Furthermore, since wake-up call effects ought to be temporary, which our evidence confirms, in addition to modeling how investors learn in response to a financial distress event it may be of relevance to conceptualize how investors gradually forget it as markets regain stability. 


\section{Acknowledgements}

This research was financially supported by a British Academy/Leverhulme Trust grant which we gratefully acknowledge. We thank an anonymous reviewer, and participants at the 9th Computational and Financial Econometrics conference, London, UK, 5th CEQURA Conference on Advances in Financial and Insurance Risk Management, Munich, Germany, 22nd International Forecasting Financial Markets Conference, Rennes, France, 21st Conference of the Society for Computational Economics, Taipei, Taiwan, and 14th INFINITI Conference on International Finance, Dublin, Ireland, as well as Orkun Saka and James Steeley for helpful comments and suggestions. Any remaining errors are our responsibility alone. We also acknowledge the technical assistance of Denis Dadimov.

\section{References}

Aguiar, M., Gopinath, G., 2006. Defaultable debt, interest rates and the current account. Journal of International Economics 69, 64-83.

Aguiar, M., Gopinath, G., 2007. Emerging market business cycles: The cycle is the trend. Journal of Political Economy 115, 69-102.

Ahnert, T., Bertsch, C., 2015. A wake-up call theory of contagion. Sveriges Riksbank, Stockholm, WP. 294.

Amato, J., Remolona, E., 2003. The credit spread puzzle. BIS Quarterly Review, December 2003, 51-63.

Ammer, J., Cai, F., 2007. Sovereign CDS and bond pricing dynamics in emerging markets: Does the cheapest-to-deliver option matter? Federal Reserve Board International Finance Discussion Paper No. 912.

Ang, A., Piazzesi, M., 2003. A no-arbitrage vector autoregression of term-structure dynamics with macroeconomic and latent variables. Journal of Monetary Economics 50, 745-787.

Arora, V., Cerisola, M., 2001. How does U.S. monetary policy influence sovereign spreads in emerging markets? IMF Staff Papers 48, 474-498.

Baldacci, E., Gupta, S., Mati, S., 2008. Is it (still) mostly fiscal? Determinants of sovereign spreads in emerging markets. IMF Working Paper 08/259, Washington D.C.

Bank of America Merrill Lynch, 2012. Guide to EM local markets. GEM Fixed Income Strategy and Economics Paper 10.

Baskaya, Y., di Giovanni, J., Kalemli-Ozcan, S., Peydro, J.-L., Ulu, M., 2017. Capital flows and the international credit channel. Journal of International Economics 108, 15-22.

Beirne, J., Fratzscher, M., 2013. The pricing of sovereign risk and contagion during the european sovereign debt crisis. Journal of International Money and Finance 34, 60-82.

Bekaert, G., Ehrmann, M., Fratzscher, M., Mehl, A., 2011. The global crisis and equity market contagion. Journal of Finance 69, 2597-2649.

Boyer, R., 2014. What we earned from the financial crisis of 2009 in emerging countries. In: Bresser-Pereira, Kregel, Burlamaqui (Eds.), Financial Stability and Growth: Perspectives on Financial Regulation and New Developmentalism. Routledge, New York. 
Bulow, J., Rogoff, K., 1989. Sovereign debt: Is to forgive to forget? American Economic Review 79, 43-50.

Bussière, M., Ristiniemi, A., 2012. Credit ratings and debt crises. Banque de France Working Paper 396, Banque de France, Paris.

Caballero, R., 2003. The future of the IMF. American Economic Review Papers and Proceedings.

Caceres, C., Guzzo, V., Segoviano, M., 2010. Sovereign spreads: Global risk aversion, contagion or fundamentals? IMF Working Paper 10/120, Washington D.C.

Campbell, J., Shiller, R., 1991. Yield spreads and interest rate movements: A bird's eye view. Review of Economics Studies 58, 479-494.

Chen, Y., Rogoff, K., 2003. Commodity currencies. Journal of International Economics 60, $133-160$.

Ciarlone, A., Piselli, P., G.Trebeschi, 2009. Emerging markets' spreads and global financial conditions. Journal of International Financial Markets, Institutions and Money 19 (1), $222-239$.

Clark, T., West, K., 2007. Approximately Normal test for equal predictive accuracy in nested models. Journal of Econometrics 138, 291-311.

Cochrane, J. H., Piazzesi, M., 2005. Bond risk premia. American Economic Review 94, $138-160$.

Comelli, F., 2012. Emerging market sovereign bond spreads: Estimation and backtesting. IMF Working Paper 12/2012, Washington D.C.

Csonto, B., Ivaschenko, I., 2013. Determinants of sovereign bond spreads in emerging markets: Local fundamentals and global factors vs. ever-changing misalignments. IMF Working Paper 13/164, Washington D.C.

Diebold, F., Li, C., 2006. Forecasting the term-structure of government bond yields. Journal of Econometrics 130, 337-364.

Diebold, F., Mariano, R., 1995. Comparing predictive accuracy. Journal of Business and Economic Statistics 253-263.

Duffie, D., Pedersen, L., Singleton, K., 2003. Modeling sovereign yield spreads: A case study of Russian debt. Journal of Finance 58, 119-159.

Eichengreen, B., Mody, A., 1998. What explains changing spreads on emerging-market debt: Fundamentals or market sentiment? NBER Working Paper 6408.

Eichengreen, B., Mody, A., Nedeljkovic, M., Sarno, L., 2012. How the Subprime Crisis went global: Evidence from bank credit default swap spreads. Journal of International Money and Finance 31.

Elton, E., Gruber, M., Agrawal, D., Mann, C., 2001. Explaining the rate spread on corporate bonds. Journal of Finance 56, 247-277.

Fama, E., Bliss, R., 1987. The information in long-maturity forward rates. American Economic Review 77, 680-692.

Ferrucci, G., 2003. Empirical determinants of emerging market economies' sovereign bond spreads. Bank of England Working Paper 205. 
Gibson, R., Sundaresan, S., 2005. Sovereign borrowing and yield spreads. University of Zurich Working Paper.

Goldman Sachs, 2007. The N-11: More than an acronym. Goldman Sachs Global Economics Paper 153.

Goldstein, M., Kaminsky, G., Reinhart, C., 2000. Assessing financial vulnerability: Developing an early warning system for emerging markets. Institute for International Economics, Washington D.C.

González-Rozada, M., Yeyati, E., 2008. Global factors and emerging market spreads. Economic Journal 118, 1917-1936.

Gray, D., Malone, S., 2008. Macrofinancial Risk Analysis. Wiley Finance, Chichester, England.

Hartelius, K., Kashiwase, K., Kodres, L., 2008. Emerging market spread compression: Is it real or is it liquidity? IMF Working Paper 08/10, Washington D.C.

Hicks, J., 1939. Value and Capital. Oxford University Press, Oxford.

Hilscher, J., Nosbusch, Y., 2010. Determinants of sovereign risk: Macroeconomic fundamentals and the pricing of sovereign debt. Review of Finance 14, 235-262.

Huang, J., Huang, M., 2012. How much of the corporate-Treasury yield spread is due to credit risk? Review of Asset Pricing Studies 2, 153-202.

IMF, 1991. World economic outlook. International Monetary Fund, Washington D.C.

IMF, 2004. Global financial stability report. Market developments and issues. September. International Monetary Fund, Washington D.C.

IMF, 2014. Global financial stability report. Market developments and issues. October. International Monetary Fund, Washington D.C.

Jaramillo, M., Tejada, C. M., 2011. Sovereign credit ratings and spreads in emerging markets: Does investment grade matter? IMF Working Paper 11/44, Washington D.C.

Krishnan, C., Ritchken, P., Thomson, J., 2010. Predicting credit spreads. Journal of Financial Intermediation 100, 304-325.

Longstaff, F., Pan, J., Pedersen, L., Singleton, K., 2011. How sovereign is sovereign risk? American Economic Journal: Macroeconomics 3, 75 -103.

Ludvigson, S., Ng, S., 2009. Macro factors in bond risk premia. Review of Financial Studies $22,5027-5067$.

Luengnaruemitchai, P., Schadler, S., 2007. Do economists' and financial markets' perspectives on the new members of the EU differ? IMF Working Paper 07/65, Washington D.C.

Lutz, F., 1940. The structure of interest rates. Quarterly Journal of Economics 55, 36-63.

Mendoza, E., 1995. The terms of trade, the real exchange rate and economic fluctuations. International Economic Review 36, 101-137.

Mendoza, E., 1997. Terms of trade uncertainty and economic growth. Journal of Development Economics 54, 323-356.

Merton, R., 2005. Swapping your country's risks. Harvard Business Review 83, 34-36. 
Min, H., 1998. The determinants of emerging market bond spreads: Do economic fundamentals matter? World Bank Policy Research Working Paper No. 1899.

Mink, M., Haan, J. D., 2013. Contagion during the greek sovereign debt crisis. Journal of International Money and Finance 34, 102-113.

Moench, M., 2008. Forecasting the yield curve in a data rich environment: A no-arbitrage factor-augmented VAR approach. Journal of Econometrics 146, 26-43.

Muth, J., 1961. Rational expectations and the theory of price movements. Econometrica 29, $315-335$.

Nelson, C., Siegel, A., 1987. Parsimonious modeling of yield curves. Journal of Business 60, $473-489$.

Neumeyer, P., Perri, F., 2005. Business cycles in emerging economies: The role of interest rates. Journal of Monetary Economics 52, 345-380.

Ongena, S., Peydro, J., Van Horen, N., 2015. Shocks abroad, pain at home? Bank-firm-level evidence on the international transmission of financial shocks. IMF Economic Review 63, $698-750$.

Pan, J., Singleton, K., 2008. Default and recovery implicit in the term-structure of sovereign CDS spreads. Journal of Finance 63, 2345-2384.

Reinhart, C., 2002. Default, currency crises, and sovereign credit ratings. World Bank Economic Review 16, 151-170.

Roll, R., 1970. The Behavior of Interest Rates: An Application of the Efficient Market Model to U.S. Treasury Bills. Basic Books, Inc., New York.

Sargent, T., 1972. Rational expectations and the term structure of interest rates. Journal of Money, Credit and Banking 4, 74-97.

Sueppel, R., 2005. Forecasting sovereign credit spreads: A cointegration model. Journal of Fixed Income 15, 54-67.

Svensson, L., 1994. Estimating and interpreting forward interest rates: Sweden 1992-1994. NBER Working Paper 48871.

Thomson, J., Ritchken, P., Krishnan, C., 2006. On credit spread slopes and predicting bank risk. Journal of Money, Credit and Banking 38, 1545-1574.

Uribe, M., Yue, V., 2006. Country spreads and emerging countries: Who drives whom? Journal of International Economics 69, 6-36. 


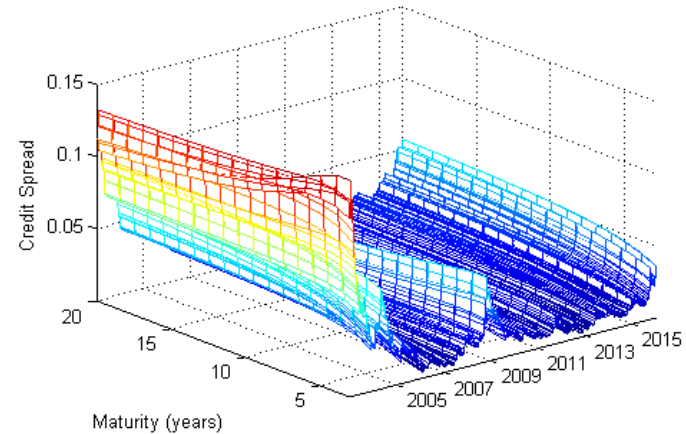

(a) Brazil

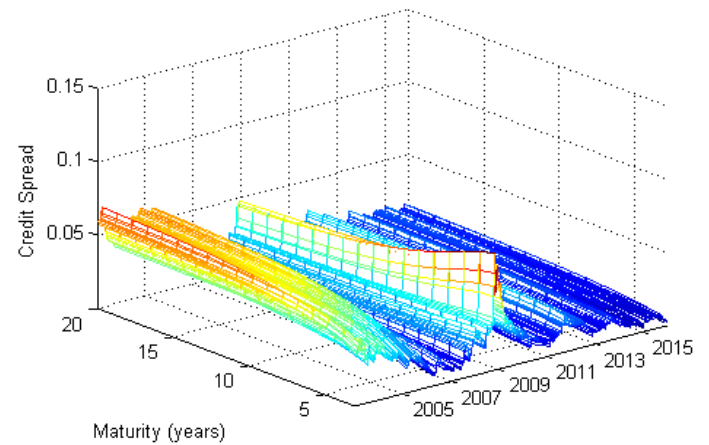

(c) Philippines

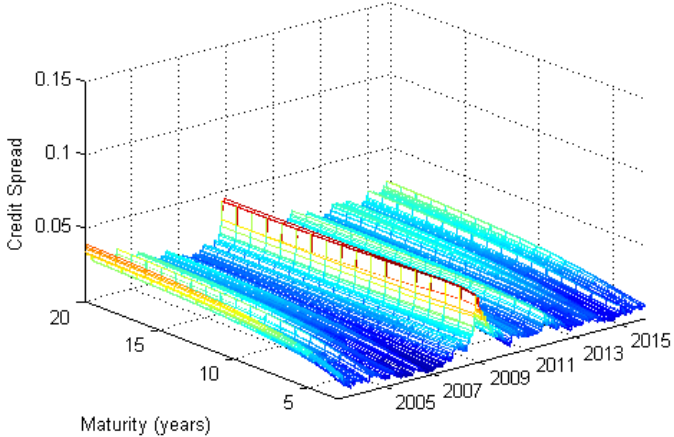

(b) Mexico



(d) Turkey

FIG.1. Emerging Market Credit Spreads

Each panel plots country credit spread curves estimated at the weekly frequency from July 1, 2003 to December 31, 2015 with cross-sections of Eurobond prices using the Nelson-Siegel decomposition method. 

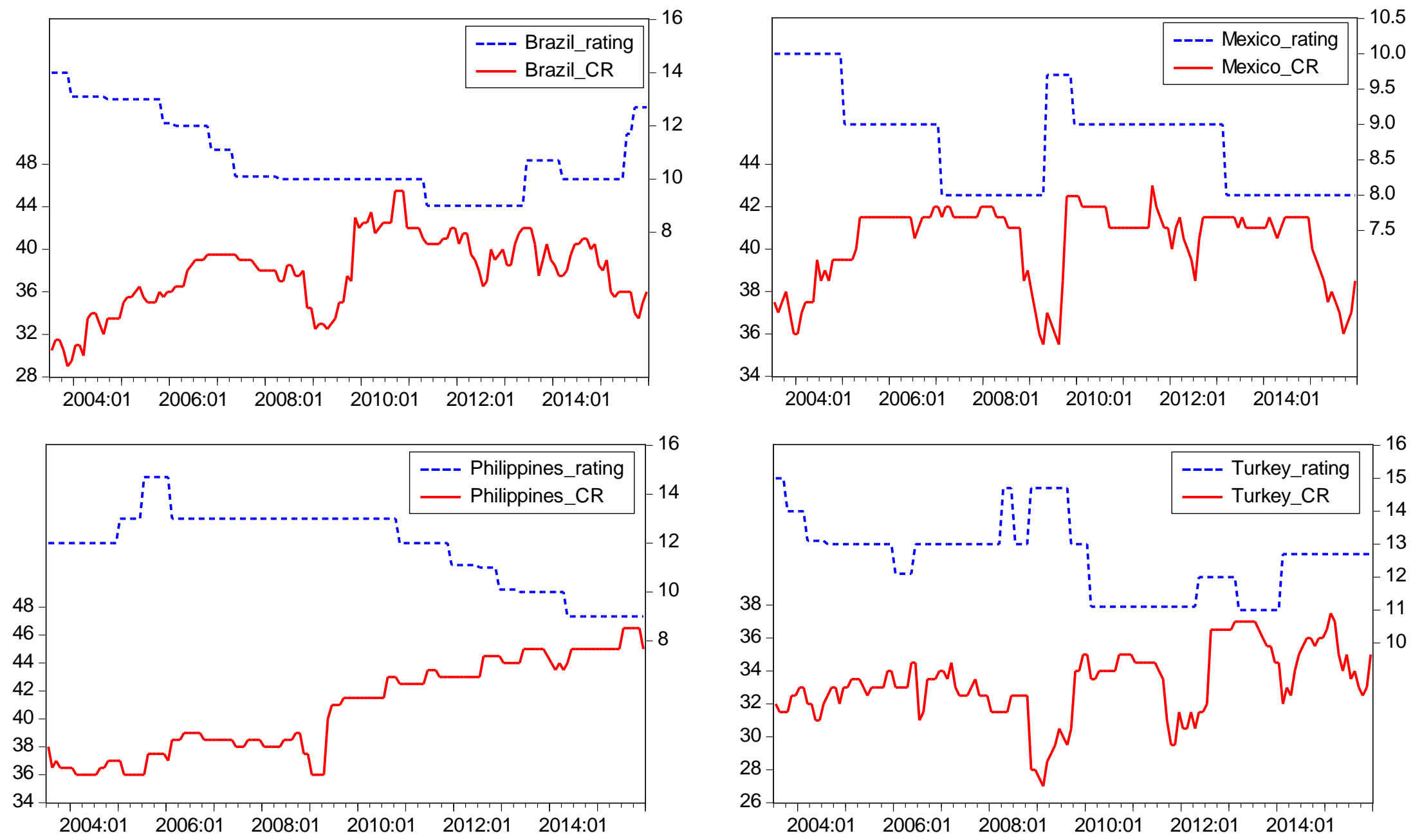

FIG.2. Country Risk and Credit Rating Outlook Index

The monthly time-series plotted are the country Financial Risk Rating provided by the Political Risk Services Group (denoted country risk, CR) and the country Credit Rating Outlook Index obtained by mapping the letter-based S\&P's long-term foreign currency ratings with rating modifiers and outlooks (denoted rating) into numerical ratings using the approach proposed by Hartelius et al. (2008). An increase in the CR (decrease in rating) value indicates higher sovereign creditworthiness. 
TABLE 1. Summary Statistics of Credit Spreads And Predictive Variables

\begin{tabular}{|c|c|c|c|c|c|c|c|c|c|c|}
\hline $\begin{array}{c}\text { Country } \\
\text { Variable }\end{array}$ & Mean & StDev & Min & Max & $\mathrm{AR}(1)$ & Mean & StDev & Min & Max & $\mathrm{AR}(1)$ \\
\hline US & \multicolumn{5}{|c|}{ Panel A: Pre-Lehman } & \multicolumn{5}{|c|}{ Panel B: Post-Lehman } \\
\hline$\beta_{f, 0}$ & 0.054 & 0.005 & 0.045 & 0.067 & 0.978 & 0.045 & 0.008 & 0.029 & 0.058 & 0.981 \\
\hline$\beta_{f, 1}$ & -0.014 & 0.019 & -0.054 & 0.010 & 0.994 & -0.027 & 0.015 & -0.053 & -0.004 & 0.981 \\
\hline$\beta_{f, 2}$ & -0.043 & 0.023 & -0.096 & -0.006 & 0.970 & -0.091 & 0.017 & -0.139 & -0.048 & 0.942 \\
\hline$\sigma_{f}^{\text {short }}$ & 0.001 & 0.001 & 0.000 & 0.005 & 0.965 & 0.000 & 0.001 & 0.000 & 0.004 & 0.933 \\
\hline \multicolumn{11}{|l|}{ Brazil } \\
\hline$s(5)$ & 0.028 & 0.018 & 0.006 & 0.080 & 0.978 & 0.015 & 0.008 & 0.004 & 0.050 & 0.939 \\
\hline$s(15)$ & 0.036 & 0.020 & 0.010 & 0.096 & 0.980 & 0.019 & 0.007 & 0.010 & 0.045 & 0.938 \\
\hline$\beta_{0}$ & 0.040 & 0.022 & 0.012 & 0.103 & 0.980 & 0.021 & 0.006 & 0.012 & 0.041 & 0.930 \\
\hline$\beta_{1}$ & -0.036 & 0.025 & -0.103 & 0.017 & 0.968 & -0.014 & 0.014 & -0.041 & 0.023 & 0.843 \\
\hline$\beta_{2}$ & -0.012 & 0.032 & -0.078 & 0.090 & 0.929 & -0.010 & 0.031 & -0.107 & 0.069 & 0.903 \\
\hline$C R$ & 35.951 & 3.012 & 29.000 & 39.500 & 0.985 & 39.806 & 3.247 & 32.500 & 45.500 & 0.972 \\
\hline$T B$ & 0.333 & 0.116 & 0.055 & 0.560 & 0.990 & 0.079 & 0.062 & -0.112 & 0.233 & 0.975 \\
\hline$\sigma_{T B}$ & 0.051 & 0.017 & 0.024 & 0.106 & 0.980 & 0.043 & 0.015 & 0.021 & 0.090 & 0.980 \\
\hline$\Delta \pi$ & 2.393 & 2.825 & -2.834 & 8.759 & 0.982 & 2.843 & 8.563 & -8.752 & 19.361 & 0.997 \\
\hline$\sigma_{\Delta T T}$ & 2.128 & 0.657 & 0.969 & 4.491 & 0.960 & 3.010 & 1.732 & 0.389 & 8.899 & 0.991 \\
\hline \multicolumn{11}{|l|}{ Mexico } \\
\hline$s(5)$ & 0.010 & 0.004 & 0.004 & 0.020 & 0.935 & 0.015 & 0.007 & 0.007 & 0.047 & 0.933 \\
\hline$s(15)$ & 0.017 & 0.005 & 0.008 & 0.031 & 0.958 & 0.019 & 0.006 & 0.011 & 0.045 & 0.923 \\
\hline$\beta_{0}$ & 0.021 & 0.006 & 0.010 & 0.039 & 0.958 & 0.020 & 0.006 & 0.013 & 0.044 & 0.903 \\
\hline$\beta_{1}$ & 0.001 & 0.015 & -0.039 & 0.040 & 0.848 & -0.014 & 0.011 & -0.044 & 0.008 & 0.790 \\
\hline$\beta_{2}$ & -0.047 & 0.027 & -0.114 & 0.022 & 0.852 & -0.005 & 0.020 & -0.062 & 0.063 & 0.795 \\
\hline$C R$ & 40.364 & 1.750 & 36.000 & 42.000 & 0.985 & 40.561 & 1.844 & 35.500 & 43.000 & 0.971 \\
\hline$T B$ & -0.076 & 0.057 & -0.287 & 0.048 & 0.964 & -0.023 & 0.061 & -0.272 & 0.085 & 0.946 \\
\hline$\sigma_{T B}$ & 0.044 & 0.023 & 0.010 & 0.102 & 0.979 & 0.052 & 0.022 & 0.024 & 0.131 & 0.980 \\
\hline$\Delta \pi$ & 3.583 & 3.487 & -3.342 & 10.567 & 0.992 & -0.233 & 10.178 & -22.243 & 19.394 & 0.998 \\
\hline$\sigma_{\Delta T T}$ & 2.065 & 0.748 & 0.909 & 4.080 & 0.985 & 4.212 & 3.280 & 1.018 & 14.099 & 0.993 \\
\hline \multicolumn{11}{|l|}{ Philippines } \\
\hline$s(5)$ & 0.026 & 0.010 & 0.008 & 0.045 & 0.981 & 0.019 & 0.011 & 0.005 & 0.067 & 0.947 \\
\hline$s(15)$ & 0.035 & 0.014 & 0.014 & 0.058 & 0.991 & 0.021 & 0.008 & 0.010 & 0.051 & 0.947 \\
\hline$\beta_{0}$ & 0.041 & 0.017 & 0.015 & 0.068 & 0.991 & 0.022 & 0.007 & 0.010 & 0.042 & 0.936 \\
\hline$\beta_{1}$ & -0.030 & 0.026 & -0.068 & 0.064 & 0.867 & -0.007 & 0.020 & -0.042 & 0.080 & 0.912 \\
\hline$\beta_{2}$ & -0.026 & 0.036 & -0.147 & 0.058 & 0.854 & -0.006 & 0.045 & -0.151 & 0.159 & 0.927 \\
\hline$C R$ & 37.535 & 1.042 & 36.000 & 39.000 & 0.977 & 42.405 & 2.208 & 36.000 & 45.000 & 0.978 \\
\hline$T B$ & -0.366 & 0.191 & -0.776 & 0.039 & 0.984 & -0.275 & 0.169 & -0.585 & 0.269 & 0.982 \\
\hline$\sigma_{T B}$ & 0.156 & 0.061 & 0.041 & 0.324 & 0.985 & 0.135 & 0.052 & 0.077 & 0.328 & 0.985 \\
\hline \multicolumn{11}{|l|}{ Turkey } \\
\hline$s(5)$ & 0.026 & 0.012 & 0.011 & 0.075 & 0.948 & 0.026 & 0.011 & 0.013 & 0.073 & 0.930 \\
\hline$s(15)$ & 0.032 & 0.010 & 0.020 & 0.078 & 0.950 & 0.028 & 0.010 & 0.014 & 0.062 & 0.949 \\
\hline$\beta_{0}$ & 0.035 & 0.010 & 0.023 & 0.079 & 0.954 & 0.029 & 0.009 & 0.013 & 0.063 & 0.952 \\
\hline$\beta_{1}$ & -0.026 & 0.016 & -0.079 & 0.006 & 0.915 & -0.006 & 0.016 & -0.055 & 0.061 & 0.747 \\
\hline$\beta_{2}$ & -0.011 & 0.041 & -0.113 & 0.118 & 0.945 & -0.002 & 0.030 & -0.124 & 0.127 & 0.757 \\
\hline$C R$ & 32.701 & 0.876 & 31.000 & 34.500 & 0.910 & 33.363 & 2.775 & 27.000 & 37.000 & 0.977 \\
\hline$T B$ & -0.774 & 0.108 & -1.065 & -0.446 & 0.978 & -0.864 & 0.239 & -1.253 & -0.202 & 0.991 \\
\hline$\sigma_{T B}$ & 0.074 & 0.030 & 0.024 & 0.149 & 0.985 & 0.099 & 0.037 & 0.042 & 0.209 & 0.984 \\
\hline$\Delta \pi$ & -0.485 & 3.357 & -7.345 & 5.405 & 0.994 & -0.460 & 4.102 & -8.864 & 8.942 & 0.993 \\
\hline$\sigma_{\Delta T T}$ & 1.869 & 0.658 & 0.795 & 3.391 & 0.987 & 2.026 & 1.247 & 0.626 & 5.320 & 0.992 \\
\hline
\end{tabular}

The table reports mean, standard deviation, minimum, maximum and 1st-order autocorrelation of 5- and 15-year bond spreads, and candidate predictors. The betas are level, slope and curvature of the U.S. yield curve (US) and credit spread curve extracted from cross-sections of bond prices sampled at the weekly

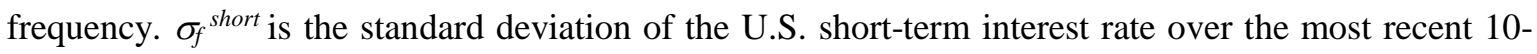
week period. $C R$ is country risk. $T B$ is trade balance. $\triangle T T$ is year-on-year terms of trade growth. $\sigma_{T B}\left(\sigma_{\Delta T T}\right)$ is the standard deviation of $T B(\triangle T T)$ over the most recent 6-month period. The pre-Lehman period is July 1, 2003 to September 14, 2008 (268 weeks) and the post-Lehman period is December 1, 2008 to December 31, 2013 (263 weeks). 
TABLE 2. Hierarchical Models for Emerging-Market Sovereign Credit Spread Prediction

\begin{tabular}{|c|c|c|c|c|c|c|c|c|c|c|c|c|}
\hline \multirow[b]{4}{*}{ MODELS } & & & & \multicolumn{4}{|c|}{ Global predictors } & \multicolumn{5}{|c|}{ Domestic predictors } \\
\hline & \multirow{2}{*}{\multicolumn{3}{|c|}{$\begin{array}{c}\text { Credit-spread-curve } \\
\text { (Level, Slope, Curvature) }\end{array}$}} & \multirow{2}{*}{\multicolumn{3}{|c|}{$\begin{array}{l}\text { U.S. yield curve factors } \\
\text { (Level, Slope, Curvature) }\end{array}$}} & \multirow{3}{*}{$\begin{array}{l}\text { Volatility of U.S. } \\
\text { short-term rate } \\
\sigma_{f}^{\text {short }}\end{array}$} & \multirow{3}{*}{$\begin{array}{c}\begin{array}{c}\text { Country risk } \\
\text { rating }\end{array} \\
C R \\
\end{array}$} & \multicolumn{2}{|c|}{ Trade balance } & \multicolumn{2}{|c|}{ Terms-of-trade growth } \\
\hline & & & & & & & & & \multirow{2}{*}{$\begin{array}{c}\text { Level } \\
T B \\
\end{array}$} & \multirow{2}{*}{$\begin{array}{c}\text { Volatility } \\
\sigma_{T B} \\
\end{array}$} & \multirow{2}{*}{$\begin{array}{l}\text { Level } \\
\Delta T T \\
\end{array}$} & \multirow{2}{*}{$\begin{array}{c}\text { Volatility } \\
\sigma_{\Delta \pi} \\
\end{array}$} \\
\hline & $\beta_{0}$ & $\beta_{1}$ & $\beta_{2}$ & $\beta_{\mathrm{f}, 0}$ & $\beta_{\mathrm{f}, 1}$ & $\beta_{\mathrm{f}, 2}$ & & & & & & \\
\hline Baseline & & $\sqrt{ }$ & & & & & & & & & & \\
\hline G1 & & $\sqrt{ }$ & & & $\sqrt{ }$ & & & & & & & \\
\hline G2 & & $\sqrt{ }$ & & & $\sqrt{ }$ & & $\sqrt{ }$ & & & & & \\
\hline GEM1 & & $\sqrt{ }$ & & & $\sqrt{ }$ & & $\sqrt{ }$ & $\sqrt{ }$ & & & & \\
\hline GEM2 & & $\sqrt{ }$ & & & $\sqrt{ }$ & & $\sqrt{ }$ & $\sqrt{ }$ & $\sqrt{ }$ & & & \\
\hline GEM3 & & $\sqrt{ }$ & & & $\sqrt{ }$ & & $\sqrt{ }$ & $\sqrt{ }$ & $\sqrt{ }$ & $\sqrt{ }$ & & \\
\hline GEM4 & & $\sqrt{ }$ & & & $\sqrt{ }$ & & $\sqrt{ }$ & $\sqrt{ }$ & $\sqrt{ }$ & $\sqrt{ }$ & $\sqrt{ }$ & \\
\hline GEM5 & & $\sqrt{ }$ & & & $\sqrt{ }$ & & $\sqrt{ }$ & $\sqrt{ }$ & $\sqrt{ }$ & $\sqrt{ }$ & $\sqrt{ }$ & $\sqrt{ }$ \\
\hline
\end{tabular}

The target variable is the emerging-market sovereign credit spread on week $t+h$ and the predictors are the variables in columns measured at week $t$. The predictive horizon $h$ is 13 weeks (one quarter) ahead. The baseline model is a regression of the 5- and 15-year spread on spread curve factors, Eq. (4). Models G1 and G2 are extensions, Eq. (5), obtained by adding the U.S. yield curve factors and the volatility of the US short-term interest rate, respectively. Models GEM1 to GEM5 are extensions, Eq. (6), obtained by adding country risk, trade balance, volatility of trade balance, terms-of-trade growth, and volatility of terms of trade growth. The credit spread curve factors and U.S. yield curve factors are extracted using the Nelson-Siegel decomposition. The global and country-specific predictors are discussed in Sections 3.2 and 3.3 of the paper, respectively. 
TABLE 3. Predictive Ability of Global Macroeconomic Variables

\begin{tabular}{|c|c|c|c|c|c|c|c|c|c|}
\hline \multirow{3}{*}{ Model } & & \multicolumn{2}{|c|}{ Brazil } & \multicolumn{2}{|c|}{ Mexico } & \multicolumn{2}{|c|}{ Philippines } & \multicolumn{2}{|c|}{ Turkey } \\
\hline & & \multicolumn{2}{|c|}{ Bond maturity } & \multicolumn{2}{|c|}{ Bond maturity } & \multicolumn{2}{|c|}{ Bond maturity } & \multicolumn{2}{|c|}{ Bond maturity } \\
\hline & & 5-years & 15 -years & 5-years & 15-years & 5-years & 15-years & 5-years & 15 -years \\
\hline & \multicolumn{9}{|c|}{ Panel A: Pre-Lehman } \\
\hline Baseline & RMSE & 57.8 & 65.4 & 35.5 & 29.8 & 59.0 & 42.5 & 40.6 & 31.5 \\
\hline \multirow[t]{2}{*}{ G1 } & Ratio RMSE & 1.54 & 1.32 & 0.76 & 0.84 & 0.85 & 0.80 & 0.85 & 0.94 \\
\hline & CW statistic & 0.46 & -0.04 & $2.48 * * *$ & $2.73 * * \star$ & $3.59 * * *$ & $4.52 * \star \star$ & $3.26 * * *$ & $2.71 * \star *$ \\
\hline \multirow[t]{3}{*}{ G2 } & Ratio RMSE & 0.87 & 0.91 & 1.02 & 0.97 & 1.07 & 1.09 & 1.03 & 0.89 \\
\hline & CW statistic & 1.42 * & 1.33 & -0.45 & 1.24 & -0.66 & -0.29 & $2.73 * * *$ & $2.43 * * *$ \\
\hline & \multicolumn{9}{|c|}{ Panel B: Post-Lehman } \\
\hline Baseline & RMSE & 33.0 & 40.7 & 24.3 & 26.2 & 27.1 & 41.6 & 47.7 & 43.8 \\
\hline \multirow[t]{2}{*}{ G1 } & Ratio RMSE & 0.95 & 0.95 & 0.82 & 0.95 & 0.88 & 0.72 & 0.88 & 0.93 \\
\hline & CW statistic & 1.93 ** & 2.36 *** & 2.75 *** & 2.28 ** & 2.08 ** & 2.98 *** & 3.78 *** & $3.39 * * *$ \\
\hline \multirow[t]{2}{*}{ G2 } & Ratio RMSE & 0.84 & 0.95 & 0.91 & 0.92 & 1.01 & 0.96 & 0.97 & 0.96 \\
\hline & CW statistic & $3.23 * \star *$ & 2.30 ** & $2.90 * * *$ & $3.09 * * *$ & -0.98 & $2.58 * \star *$ & 1.32 * & 1.91 ** \\
\hline
\end{tabular}

The first row in each panel reports the RMSE of the baseline credit spread curve model. The following rows show the ratio of RMSEs of the model at hand and the preceding (nested) model. Ratio RMSE $<1$ indicates that the additional global macroeconomic predictors in the extended model bring a forecast error reduction vis-à-vis the preceding model. Significance of the mean error differential is tested with the Clark and West (2007; CW) $t$-statistic for the null hypothesis that the predictive ability of the extended model is not superior to that of the preceding model; $H_{0}: M S E_{\text {base }} \leq M S E_{G 1}$ vs. $H_{A}: M S E_{\text {base }}>M S E_{G 1}$ for model $G 1$ and $H_{0}: M S E_{G 1} \leq M S E_{G 2}$ Vs. $H_{A}: M S E_{G 1}>M S E_{G 2}$ for model $G 2 .{ }^{* * *}$, ** and * denotes rejection at the $10 \%, 5 \%$ or $1 \%$ level, respectively. Table 2 lists all the models. Estimation is based on weekly data and the forecast horizon is $h=13$ weeks (quarter ahead). Bond maturity is $\tau=\{5,15\}$ years. The forecast evaluation period is November 28, 2006 to September 14, 2008 (92 forecasts; pre-Lehman) in Panel A and March 27, 2012 to December, 2013 (90 forecasts; post-Lehman) in Panel B. 
TABLE 4. Benchmarking the Predictive Ability of Global Macroeconomic Variables

\begin{tabular}{|c|c|c|c|c|c|c|c|c|c|}
\hline \multirow{2}{*}{ Model } & & \multicolumn{2}{|c|}{ 5-year spread } & \multicolumn{2}{|c|}{ 15-year spread } & \multicolumn{2}{|c|}{ 5-year spread } & \multicolumn{2}{|c|}{ 15-year spread } \\
\hline & & RW & SR & RW & SR & RW & SR & RW & SR \\
\hline & \multicolumn{9}{|c|}{ Panel A: Pre-Lehman } \\
\hline & & \multicolumn{4}{|c|}{ Brazil } & \multicolumn{4}{|c|}{ Mexico } \\
\hline Benchmark & RMSE & 49.5 & 50.3 & 47.0 & 50.9 & 39.6 & 38.0 & 31.6 & 30.9 \\
\hline \multirow[t]{2}{*}{ Baseline } & Ratio RMSE & 1.17 & 1.15 & 1.39 & 1.29 & 0.90 & 0.93 & 0.94 & 0.97 \\
\hline & DM stat. & -1.37 & -1.96 & -2.71 & -2.86 & $2.77 * * *$ & 1.29 & 0.94 & 0.55 \\
\hline \multirow[t]{2}{*}{ G1 } & Ratio RMSE & 1.80 & 1.77 & 1.84 & 1.68 & 0.68 & 0.71 & 0.79 & 0.81 \\
\hline & DM stat. & -2.18 & -2.37 & -2.94 & -3.17 & $2.80 * \star \star$ & $3.26 * \star \star$ & 1.89 * & 2.49 ** \\
\hline \multirow[t]{3}{*}{$G 2$} & Ratio RMSE & 1.56 & 1.54 & 1.67 & 1.54 & 0.70 & 0.72 & 0.77 & 0.79 \\
\hline & DM stat. & -1.97 & -2.11 & -3.07 & -3.19 & 2.58 ** & $3.03 * \star *$ & 2.14 ** & 2.54 ** \\
\hline & & \multicolumn{4}{|c|}{ Philippines } & \multicolumn{4}{|c|}{ Turkey } \\
\hline Benchmark & RMSE & 60.9 & 59.0 & 39.0 & 38.6 & 46.3 & 48.9 & 33.1 & 33.5 \\
\hline \multirow[t]{2}{*}{ Baseline } & Ratio RMSE & 0.97 & 1.00 & 1.09 & 1.10 & 0.88 & 0.83 & 0.95 & 0.94 \\
\hline & DM stat. & 0.90 & 0.03 & -0.80 & -1.00 & 1.15 & 1.24 & 0.43 & 0.44 \\
\hline \multirow[t]{2}{*}{ G1 } & Ratio RMSE & 0.83 & 0.85 & 0.87 & 0.88 & 0.75 & 0.71 & 0.89 & 0.88 \\
\hline & DM stat. & 1.99 ** & 2.17 ** & 1.33 & 1.37 & 2.09 ** & 2.97 *** & 0.92 & 0.97 \\
\hline \multirow[t]{4}{*}{$G 2$} & Ratio RMSE & 0.88 & 0.91 & 0.95 & 0.96 & 0.77 & 0.73 & 0.79 & 0.78 \\
\hline & DM stat. & 0.99 & 0.86 & 0.43 & 0.37 & 2.02 ** & 1.99 ** & 1.95 * & 1.90 * \\
\hline & \multicolumn{9}{|c|}{ Panel B: Post-Lehman } \\
\hline & & \multicolumn{4}{|c|}{ Brazil } & \multicolumn{4}{|c|}{ Mexico } \\
\hline Benchmark & RMSE & 34.6 & 36.7 & 43.9 & 47.0 & 26.3 & 26.9 & 29.0 & 32.0 \\
\hline \multirow[t]{2}{*}{ Baseline } & Ratio RMSE & 0.95 & 0.90 & 0.93 & 0.87 & 0.93 & 0.90 & 0.91 & 0.82 \\
\hline & DM stat. & 0.50 & 0.61 & 0.86 & 1.56 & 1.17 & 1.08 & 1.00 & $2.00 * *$ \\
\hline \multirow[t]{2}{*}{ G1 } & Ratio RMSE & 0.91 & 0.85 & 0.88 & 0.82 & 0.75 & 0.74 & 0.86 & 0.78 \\
\hline & DM stat. & 0.79 & 1.17 & 1.28 & $2.40 * *$ & 1.87 * & 2.54 ** & 1.09 & 3.44 *** \\
\hline \multirow[t]{3}{*}{ G2 } & Ratio RMSE & 0.76 & 0.71 & 0.83 & 0.78 & 0.69 & 0.67 & 0.79 & 0.72 \\
\hline & DM stat. & 2.46 ** & 2.15 ** & 2.21 ** & $3.79 * \star \star$ & 2.46 ** & $2.81 * \star \star$ & 1.89 * & $3.68 * \star *$ \\
\hline & & \multicolumn{4}{|c|}{ Philippines } & \multicolumn{4}{|c|}{ Turkey } \\
\hline Benchmark & RMSE & 31.4 & 38.2 & 41.2 & 42.0 & 63.8 & 59.3 & 58.2 & 57.0 \\
\hline \multirow[t]{2}{*}{ Baseline } & Ratio RMSE & 0.86 & 0.71 & 1.01 & 0.99 & 0.75 & 0.80 & 0.75 & 0.77 \\
\hline & DM stat. & 2.27 ** & 2.48 ** & -0.01 & 0.06 & 2.42 ** & 2.22 ** & 2.19 ** & 2.43 ** \\
\hline \multirow[t]{2}{*}{ G1 } & Ratio RMSE & 0.76 & 0.62 & 0.72 & 0.71 & 0.66 & 0.71 & 0.70 & 0.71 \\
\hline & DM stat. & 2.08 ** & 3.45 *** & 2.11 ** & 2.62 ** & 2.59 ** & $2.52 * \star \star$ & 2.19 ** & $2.43 * *$ \\
\hline G2 & Ratio RMSE & 0.77 & 0.63 & 0.69 & 0.68 & 0.64 & 0.69 & 0.67 & 0.68 \\
\hline & DM stat. & 2.00 ** & $3.41^{* * *}$ & 2.36 ** & $2.97 * \star \star$ & $2.82 * * *$ & $2.78^{* * *}$ & $2.55^{* * *}$ & $2.84^{\star \star \star}$ \\
\hline
\end{tabular}

The table reports the RMSE of the benchmark random walk (RW) and slope-regression (SR) models and the ratio of RMSEs of the model at hand to the benchmark. A ratio RMSE $<1$ indicates that the model brings a forecast error reduction versus the benchmark. Significance of the forecast accuracy gains is assessed with the Diebold and Mariano (1995) $t$-statistic for the null hypothesis of equal mean squared error; $H_{0}: M S E_{\text {bench }}-M S E_{m}=0$ vs. $H_{A}: M S E_{\text {bench }}-M S E_{m} \neq 0 . *$, ** and $* * *$ denote rejection at the $10 \%, 5 \%$ or $1 \%$ level, respectively. Table 2 lists all the models. Estimation is based on weekly data and the forecast horizon is $h=13$ weeks (quarter-ahead). Bond maturity is $\tau=\{5,15\}$ years. The forecast evaluation period is November 28, 2006 to September 14, 2008 (92 forecasts; pre-Lehman) in Panel A, and March 27, 2012 to December 31, 2013 (90 forecasts; post-Lehman) in Panel B. 
TABle 5. Predictive Ability of Domestic Macroeconomic Variables

\begin{tabular}{|c|c|c|c|c|c|c|c|c|c|}
\hline \multirow{3}{*}{ Model } & & \multirow{2}{*}{\multicolumn{2}{|c|}{$\frac{\text { Brazil }}{\text { Bond maturity }}$}} & \multirow{2}{*}{\multicolumn{2}{|c|}{$\frac{\text { Mexico }}{\text { Bond maturity }}$}} & \multirow{2}{*}{\multicolumn{2}{|c|}{$\begin{array}{c}\text { Philippines } \\
\text { Bond maturity }\end{array}$}} & \multirow{2}{*}{\multicolumn{2}{|c|}{$\frac{\text { Turkey }}{\text { Bond maturity }}$}} \\
\hline & & & & & & & & & \\
\hline & & 5-years & 15 -years & 5-years & 15 -years & \multirow[t]{2}{*}{ 5-years } & \multirow[t]{2}{*}{15 -years } & \multirow[t]{2}{*}{ 5-years } & \multirow[t]{2}{*}{ 15-years } \\
\hline & & & & Panel & 4: Pre-Leh & & & & \\
\hline G2 & RMSE & 77.4 & 78.6 & 27.6 & 24.4 & 53.8 & 37.0 & 35.5 & 26.1 \\
\hline \multirow[t]{2}{*}{ GEM1 } & Ratio RMSE & 0.82 & 0.87 & 1.00 & 0.95 & 0.99 & 0.91 & 0.99 & 1.03 \\
\hline & CW statistic & 2.59 *** & 2.31 ** & -0.18 & 2.20 ** & 1.05 & 2.82 *** & 1.22 & -1.86 \\
\hline \multirow[t]{2}{*}{ GEM2 } & Ratio RMSE & 1.12 & 1.07 & 1.05 & 1.04 & 0.99 & 1.01 & 1.03 & 1.10 \\
\hline & CW statistic & -4.01 & -2.64 & -0.35 & -0.49 & 0.98 & -0.48 & 1.04 & 0.29 \\
\hline \multirow[t]{2}{*}{ GEM3 } & Ratio RMSE & 0.96 & 1.00 & 1.04 & 1.04 & 0.99 & 0.97 & 1.10 & 0.93 \\
\hline & CW statistic & $2.55 * * \star$ & -0.43 & -1.43 & 0.30 & 1.29 * & 1.45 * & -1.85 & 2.22 ** \\
\hline \multirow[t]{2}{*}{ GEM4 } & Ratio RMSE & 1.01 & 1.01 & 1.00 & 1.00 & & & 0.84 & 1.31 \\
\hline & CW statistic & 0.42 & 1.03 & 0.33 & 0.60 & & & $3.58 * \star *$ & -1.65 \\
\hline \multirow[t]{3}{*}{ GEM5 } & Ratio RMSE & 1.07 & 1.04 & 0.98 & 1.00 & & & 1.06 & 1.00 \\
\hline & CW statistic & -0.77 & -0.53 & 1.19 & 0.19 & & & 1.29 * & 0.86 \\
\hline & \multicolumn{9}{|c|}{ Panel B: Post-Lehman } \\
\hline$G 2$ & RMSE & 26.2 & 36.5 & 18.0 & 22.9 & 24.1 & 28.5 & 40.8 & 38.8 \\
\hline \multirow[t]{2}{*}{ GEM1 } & Ratio RMSE & 1.02 & 1.03 & 1.09 & 1.00 & 0.97 & 0.97 & 1.07 & 1.05 \\
\hline & CW statistic & -0.60 & -1.51 & -2.47 & -0.10 & 2.31 ** & $2.51 * \star \star$ & 1.83 ** & $1.76^{* *}$ \\
\hline \multirow[t]{2}{*}{ GEM2 } & Ratio RMSE & 0.99 & 0.99 & 1.09 & 1.02 & 1.04 & 1.01 & 0.97 & 0.96 \\
\hline & CW statistic & 0.76 & 0.78 & 0.06 & -1.19 & 0.13 & 0.08 & 1.15 & 1.12 \\
\hline \multirow[t]{2}{*}{ GEM3 } & Ratio RMSE & 0.97 & 0.96 & 0.96 & 0.84 & 0.99 & 1.00 & 0.81 & 0.86 \\
\hline & CW statistic & 1.62 * & 2.13 ** & 1.58 * & 2.71 *** & 0.88 & -0.27 & 3.38 *** & $2.45^{* * *}$ \\
\hline \multirow[t]{2}{*}{ GEM4 } & Ratio RMSE & 1.03 & 0.95 & 1.01 & 1.04 & & & 0.99 & 0.94 \\
\hline & CW statistic & 0.40 & $2.07 * *$ & -0.08 & -1.23 & & & 1.16 & 1.91 ** \\
\hline \multirow[t]{2}{*}{ GEM5 } & Ratio RMSE & 0.96 & 0.95 & 0.97 & 1.01 & & & 1.02 & 1.01 \\
\hline & CW statistic & 1.41 * & 2.68 *** & 1.84 ** & -1.40 & & & -2.38 & -1.38 \\
\hline
\end{tabular}

The first row in each panel reports the RMSE of model $G 2$ with predictors the spread curve factors and global variables (U.S. yield curve factors and U.S. short-term interest rate volatility). The subsequent rows report the ratio of RMSEs of the model at hand and the preceding (nested) model. A ratio RMSE $<1$ indicates that the additional country-specific predictor in the model at hand reduces forecast errors versus the preceding model. Significance of the error reduction is assessed with the Clark and West (2007; CW) $t$-test for the null hypothesis that that the predictive ability of the extended model is not superior to that of the preceding nested model; e.g. $H_{0}: M S E_{G 2} \leq M S E_{G E M 1}$ vs. $H_{A}: M S E_{G 2}>M S E_{G E M 1}$ for model GEM1 and $H_{0}: M S E_{G E M 1} \leq M S E_{G E M 2}$ vs. $H_{A}: M S E_{G E M 1}>M S E_{G E M 2}$ for model GEM2. ***, ** and * denote rejection at the $10 \%, 5 \%$ or $1 \%$ level, respectively. Table2 lists all the models. Models GEM4 and GEM5 are precluded for Philippines due to data limitations for terms-of-trade. Estimation is based on weekly data. The forecast horizon is $h=13$ weeks. Bond maturity is $\tau=\{5,15\}$ years. The forecast evaluation period is November 28, 2006 to September 14, 2008 (92 forecasts; pre-Lehman) in Panel A, and March 27, 2012 to December 31, 2013 (90 forecasts; post-Lehman) in Panel B. 


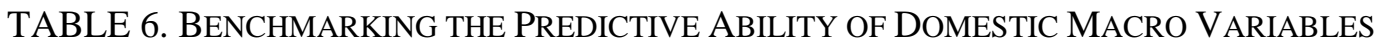

\begin{tabular}{|c|c|c|c|c|c|c|c|c|c|}
\hline \multirow[t]{2}{*}{ Model } & & \multicolumn{2}{|c|}{ 5-year spread } & \multicolumn{2}{|c|}{ 15-year spread } & \multicolumn{2}{|c|}{ 5-year spread } & \multicolumn{2}{|c|}{ 15-year spread } \\
\hline & & RW & SR & RW & SR & RW & SR & RW & SR \\
\hline & \multicolumn{9}{|c|}{ Panel A: Pre-Lehman } \\
\hline & & & Braz & & & & $\mathrm{Me}$ & & \\
\hline \multirow[t]{2}{*}{ GEM1 } & Ratio RMSE & 1.28 & 1.26 & 1.46 & 1.35 & 0.70 & 0.73 & 0.73 & 0.75 \\
\hline & DM stat. & -1.40 & -1.62 & -3.35 & -3.65 & $2.61 * \star$ & $3.03 * * *$ & $2.61 * * *$ & $2.75^{* * *}$ \\
\hline \multirow[t]{2}{*}{ GEM2 } & RMSE Ratio & 1.43 & 1.41 & 1.56 & 1.44 & 0.73 & 0.76 & 0.76 & 0.78 \\
\hline & DM stat. & -2.29 & -2.76 & -4.01 & -4.32 & $2.35 * \star$ & $2.87^{* * *}$ & $2.27^{* *}$ & 2.39 ** \\
\hline \multirow[t]{2}{*}{ GEM3 } & Ratio RMSE & 1.37 & 1.34 & 1.56 & 1.44 & 0.76 & 0.79 & 0.79 & 0.81 \\
\hline & DM stat. & -2.16 & -2.69 & -3.99 & -4.33 & $2.01 * \star$ & $2.36^{* *}$ & 2.02 ** & $2.69 * \star *$ \\
\hline \multirow[t]{2}{*}{ GEM4 } & Ratio RMSE & 1.38 & 1.36 & 1.58 & 1.46 & 0.76 & 0.79 & 0.79 & 0.80 \\
\hline & DM stat. & -2.14 & -2.56 & -3.29 & -3.48 & $2.10 * \star$ & 2.50 ** & 2.02 ** & $2.99 * \star \star$ \\
\hline \multirow[t]{3}{*}{ GEM5 } & Ratio RMSE & 1.48 & 1.46 & 1.65 & 1.52 & 0.75 & 0.78 & 0.79 & $0.81 * \star *$ \\
\hline & DM stat. & -2.61 & -2.86 & -3.62 & -3.58 & 2.20 ** & $2.57^{* *}$ & 1.93 * & 2.68 \\
\hline & & \multicolumn{4}{|c|}{ Philippines } & \multicolumn{4}{|c|}{ Turkey } \\
\hline \multirow[t]{2}{*}{ GEM1 } & RMSE Ratio & 0.87 & 0.90 & 0.86 & 0.87 & 0.76 & 0.72 & 0.82 & 0.80 \\
\hline & DM stat. & 1.12 & 1.02 & 1.20 & 1.20 & 2.03 ** & 2.03 ** & 1.76 * & 1.70 * \\
\hline \multirow[t]{2}{*}{ GEM2 } & Ratio RMSE & 0.99 & 0.89 & 1.01 & 0.88 & 0.78 & 0.74 & 0.90 & 0.88 \\
\hline & DM stat. & 1.18 & 1.15 & 1.11 & 1.12 & 1.66 & 1.92 * & 0.81 & 0.95 \\
\hline \multirow[t]{2}{*}{ GEM3 } & Ratio RMSE & 0.99 & 0.88 & 0.97 & 0.85 & 0.86 & 0.81 & 0.84 & 0.82 \\
\hline & DM stat. & 1.31 & 1.33 & 1.32 & 1.34 & 1.01 & 1.39 & 1.34 & 1.81 * \\
\hline \multirow[t]{2}{*}{ GEM4 } & & & & & & 0.72 & 0.68 & 1.09 & 1.08 \\
\hline & & & & & & 1.96 * & $2.14^{* *}$ & -0.60 & -0.76 \\
\hline \multirow[t]{4}{*}{ GEM5 } & & & & & & 0.76 & 0.72 & 1.09 & 1.08 \\
\hline & & & & & & 1.53 & 1.81 * & -0.51 & -0.50 \\
\hline & \multicolumn{9}{|c|}{ Panel B: Post-Lehman } \\
\hline & & \multicolumn{4}{|c|}{ Brazil } & & $\mathrm{Me}$ & & \\
\hline GEM1 & RMSE Ratio & 0.77 & 0.73 & 0.85 & 0.80 & 0.75 & 0.73 & 0.79 & 0.72 \\
\hline & DM stat. & 2.56 ** & 2.00 ** & 2.10 ** & 3.32 *** & 2.32 ** & $2.55^{* *}$ & 1.87 * & $3.73 * \star \star$ \\
\hline GEM2 & Ratio RMSE & 0.76 & 0.72 & 0.85 & 0.79 & 0.82 & 0.80 & 0.81 & 0.73 \\
\hline & DM stat. & $2.73^{* * *}$ & 1.97 * & 2.38 ** & 3.31 *** & 1.45 & 1.77 * & 1.73 * & $3.46 * \star *$ \\
\hline GEM3 & RMSE Ratio & 0.74 & 0.70 & 0.81 & 0.76 & 0.78 & 0.76 & 0.67 & 0.61 \\
\hline & DM stat. & $2.89 * * \star$ & 2.04 ** & $2.79 * \star \star$ & 3.24 *** & 1.61 & 1.82 * & 2.62 ** & $3.35 * \star *$ \\
\hline GEM4 & Ratio RMSE & 0.76 & 0.72 & 0.77 & 0.72 & 0.79 & 0.77 & 0.70 & 0.64 \\
\hline & DM stat. & 2.30 ** & 1.82 * & $2.75^{\star * \star}$ & 3.23 *** & 1.55 & 1.80 * & 2.35 ** & $3.26 * \star \star$ \\
\hline GEM5 & Ratio RMSE & 0.74 & 0.69 & 0.73 & 0.68 & 0.77 & 0.75 & 0.71 & 0.64 \\
\hline & DM stat. & 2.52 ** & 1.92 * & 2.95 *** & 3.44 *** & 1.67 * & 1.89 * & 2.33 ** & 3.24 *** \\
\hline & & & Philip & oines & & & Tur & & \\
\hline GEM1 & RMSE Ratio & 0.75 & 0.61 & 0.67 & 0.66 & 0.68 & 0.73 & 0.70 & 0.72 \\
\hline & DM stat. & $2.24 * *$ & $3.64 * \star *$ & 2.49 ** & $3.11 * * \star$ & $2.29 * *$ & 2.56 ** & 2.14 ** & 2.82 *** \\
\hline GEM2 & Ratio RMSE & 1.04 & 0.64 & 1.01 & 0.66 & 0.66 & 0.71 & 0.68 & 0.69 \\
\hline & DM stat. & 2.02 ** & $3.77^{* * *}$ & 2.47 ** & $3.18^{* * \star}$ & 2.32 ** & 2.26 ** & 2.24 ** & 2.60 ** \\
\hline GEM3 & RMSE Ratio & 0.99 & 0.63 & 1.00 & 0.67 & 0.54 & 0.58 & 0.58 & 0.60 \\
\hline & DM stat. & $2.43 * *$ & 3.63 *** & $2.48^{* *}$ & $3.10 * * *$ & $2.79 * \star \star$ & $2.66 * * *$ & 2.58 ** & 2.68 *** \\
\hline GEM4 & Ratio RMSE & & & & & 0.53 & 0.57 & 0.55 & 0.56 \\
\hline & DM stat. & & & & & $2.84 * \star \star$ & $2.68^{* \star *}$ & $2.77^{* \star *}$ & $2.79 * \star \star$ \\
\hline GEM5 & Ratio RMSE & & & & & 0.54 & 0.58 & 0.56 & 0.57 \\
\hline & DM stat. & & & & & 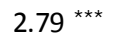 & 2.61 ** & $2.75 * \star *$ & $2.73 * \star \star$ \\
\hline
\end{tabular}

The table reports the ratio of RMSEs of the model at hand versus the benchmark random walk (RW) and slope-regression (SR). Significance is assessed through the Diebold and Mariano (1995) $t$-test for the null hypothesis $H_{0}: M S E_{\text {bench }}-M S E_{m}=0$ vs. $H_{0}: M S E_{\text {bench }}-M S E_{m} \neq 0$. $^{*}$, $^{* *}$ and $* * *$ denotes rejection at the $10 \%, 5 \%$ or $1 \%$ level, respectively. Table 2 lists all the models. Estimation is based on weekly data and the forecast horizon is $h=13$ weeks (quarter ahead). Bond maturity is $\tau=\{5,15\}$ years. The forecast evaluation period is November 28, 2006 to September 14, 2008 (92 forecasts; pre-Lehman) in Panel A, and March 27, 2012 to December 31, 2013 (90 forecasts; post-Lehman) in Panel B. 
TABLE 7. Predictive Ability of Macroeconomic VARiables: Post-Lehman EXTENDED

\begin{tabular}{|c|c|c|c|c|c|c|c|c|c|}
\hline \multirow{3}{*}{ Model } & & \multicolumn{2}{|c|}{ Brazil } & \multicolumn{2}{|c|}{ Mexico } & \multicolumn{2}{|c|}{ Philippines } & \multicolumn{2}{|c|}{ Turkey } \\
\hline & & \multicolumn{2}{|c|}{ Bond maturity } & \multicolumn{2}{|c|}{ Bond maturity } & \multicolumn{2}{|c|}{ Bond maturity } & \multicolumn{2}{|c|}{ Bond maturity } \\
\hline & & 5-years & 15 -years & 5-years & 15 -years & 5-years & 15 -years & 5-years & 15 -years \\
\hline & \multicolumn{9}{|c|}{ Panel A: Global variables } \\
\hline Baseline & RMSE & 57.2 & 63.2 & 20.1 & 28.1 & 22.4 & 23.2 & 42.4 & 43.8 \\
\hline \multirow[t]{2}{*}{ G1 } & Ratio RMSE & 1.01 & 1.04 & 1.08 & 1.05 & 0.98 & 1.12 & 1.36 & 1.26 \\
\hline & CW statistic & 0.80 & -0.60 & 0.28 & -0.27 & $3.02 * * \star$ & 1.19 & 0.35 & -0.53 \\
\hline \multirow[t]{3}{*}{ G2 } & Ratio RMSE & 0.94 & 0.97 & 0.99 & 0.95 & 1.01 & 0.95 & 0.86 & 0.85 \\
\hline & CW statistic & 1.94 ** & 1.47 * & 1.42 * & $2.15 * *$ & -2.10 & $2.59 * \star \star$ & $4.28 * * *$ & $4.85 * * *$ \\
\hline & \multicolumn{9}{|c|}{ Panel B: Domestic variables } \\
\hline \multirow[t]{2}{*}{ GEM1 } & Ratio RMSE & 0.99 & 1.00 & 1.02 & 0.99 & 1.01 & 1.00 & 1.07 & 1.05 \\
\hline & CW statistic & 1.31 * & 0.89 & -1.11 & 0.78 & 0.11 & 0.57 & -1.24 & -0.72 \\
\hline \multirow[t]{2}{*}{ GEM2 } & Ratio RMSE & 0.96 & 0.98 & 1.02 & 0.97 & 1.09 & 1.04 & 0.85 & 0.88 \\
\hline & CW statistic & 1.38 * & 1.24 & -0.03 & 1.74 ** & -0.64 & -1.50 & $2.66 * \star \star$ & $2.63 * \star \star *$ \\
\hline \multirow[t]{2}{*}{ GEM3 } & Ratio RMSE & 0.97 & 0.93 & 1.06 & 1.07 & 0.97 & 1.00 & 1.01 & 1.00 \\
\hline & CW statistic & 0.96 & 1.26 & -1.03 & -0.37 & 1.42 * & 0.09 & 0.70 & 0.71 \\
\hline \multirow[t]{2}{*}{ GEM4 } & Ratio RMSE & 1.00 & 1.00 & 0.93 & 0.98 & & & 0.99 & 0.96 \\
\hline & CW statistic & 0.34 & 0.69 & $2.05 * *$ & 1.95 ** & & & 0.83 & 1.57 * \\
\hline \multirow[t]{2}{*}{ GEM5 } & Ratio RMSE & 1.00 & 1.02 & 0.93 & 0.97 & & & 1.00 & 0.99 \\
\hline & CW statistic & 0.10 & -0.76 & $2.59 * \star \star$ & 2.19 ** & & & -0.27 & 1.21 \\
\hline
\end{tabular}

The first row in panel A reports the RMSE of the baseline credit spread curve model. The following rows across both panels show the ratio of RMSEs of the model at hand and the preceding (nested) model. A ratio RMSE $<1$ indicates that the additional global macroeconomic predictors in the extended model bring a forecast error reduction vis-à-vis the preceding model. Significance of the mean error differential is tested with the Clark and West (2007; CW) $t$-statistic for the null hypothesis that the predictive ability of the extended model is not superior to that of the preceding model; $H_{0}: M S E_{\text {base }}-M S E_{G 1}=0$ vs. $H_{0}: M S E_{\text {base }}$ $M S E_{G 1} \neq 0$ for model $G 1 ; H_{0}: M S E_{G 1}-M S E_{G 2}=0$ vs. $H_{0}: M S E_{G 1}-M S E_{G 2} \neq 0$ for model $G 2$ and so on. $* * *, * *$ and $*$ denotes rejection at the $10 \%, 5 \%$ or $1 \%$ level, respectively. Table 2 lists all the models. Estimation is based on weekly data and the forecast horizon is $h=13$ weeks (quarter ahead). Bond maturity is $\tau=\{5,15\}$ years. The forecast evaluation period is July 30, 2013 to December 31, 2015 (127 forecasts). 


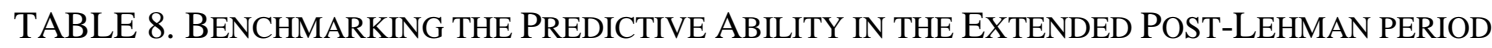

\begin{tabular}{|c|c|c|c|c|c|c|c|c|c|c|c|c|c|c|c|c|c|}
\hline \multirow[b]{3}{*}{ Model } & & \multicolumn{4}{|c|}{ Brazil } & \multicolumn{4}{|c|}{ Mexico } & \multicolumn{4}{|c|}{ Philippines } & \multicolumn{4}{|c|}{ Turkey } \\
\hline & & \multicolumn{2}{|c|}{ 5-year spread } & \multicolumn{2}{|c|}{ 15-year spread } & \multicolumn{2}{|c|}{ 5-year spread } & \multicolumn{2}{|c|}{ 15-year spread } & \multicolumn{2}{|c|}{ 5-year spread } & \multicolumn{2}{|c|}{15 -year spread } & \multicolumn{2}{|c|}{ 5-year spread } & \multicolumn{2}{|c|}{ 15-year spread } \\
\hline & & RW & SR & RW & SR & RW & SR & RW & $S R$ & RW & SR & RW & SR & RW & SR & RW & SR \\
\hline & \multicolumn{17}{|c|}{ Panel A: Baseline and global variables } \\
\hline Benchmark & RMSE & 63.0 & 70.4 & 61.9 & 60.6 & 22.5 & 23.1 & 26.3 & 37.0 & 20.4 & 26.6 & 25.5 & 27.9 & 50.4 & 55.2 & 46.3 & 52.2 \\
\hline \multirow[t]{2}{*}{ Baseline } & Ratio RMSE & 0.91 & 0.81 & 1.02 & 1.04 & 0.89 & 0.87 & 1.07 & 0.76 & 1.10 & 0.84 & 0.91 & 0.83 & 0.84 & 0.77 & 0.95 & 0.84 \\
\hline & DM stat. & 2.42 ** & 2.52 ** & -0.56 & -1.06 & $2.77^{* * *}$ & 1.34 & -0.92 & $5.95 * * *$ & -1.28 & 1.09 & 0.80 & 1.01 & 1.94 * & $3.51 * * *$ & 0.64 & 2.41 ** \\
\hline \multirow[t]{2}{*}{ G1 } & Ratio RMSE & 0.92 & 0.82 & 1.06 & 1.08 & 0.97 & 0.94 & 1.12 & 0.80 & 1.08 & 0.83 & 1.02 & 0.93 & 1.15 & 1.05 & 1.19 & 1.06 \\
\hline & DM stat. & 1.40 & 1.91 * & -1.42 & -1.64 & 0.61 & 0.53 & -1.44 & $5.20 * \star *$ & -1.16 & 1.31 & -0.17 & 0.42 & -1.25 & -0.47 & -1.85 & -0.58 \\
\hline \multirow[t]{3}{*}{ G2 } & Ratio RMSE & 0.87 & 0.78 & 1.03 & 1.05 & 0.96 & 0.93 & 1.06 & 0.76 & 1.09 & 0.84 & 0.98 & 0.89 & 0.99 & 0.91 & 0.87 & 0.90 \\
\hline & DM stat. & 1.71 * & 1.93 * & -0.53 & -1.02 & 0.82 & 0.59 & -0.97 & 5.76 *** & -1.32 & 1.25 & 0.19 & 0.70 & 0.08 & 0.99 & 1.72 * & 1.11 \\
\hline & \multicolumn{17}{|c|}{ Panel B: Domestic variables } \\
\hline \multirow[t]{2}{*}{ GEM1 } & Ratio RMSE & 0.86 & 0.77 & 1.02 & 1.04 & 0.98 & 0.95 & 1.06 & 0.75 & 1.09 & 0.84 & 0.98 & 0.89 & 1.07 & 0.97 & 1.07 & 0.95 \\
\hline & DM stat. & 1.81 * & $1.99 * *$ & -0.44 & -0.98 & 0.42 & 0.41 & -0.88 & $5.89 * * \star$ & -1.22 & 1.20 & 0.18 & 0.68 & -0.79 & 0.32 & -1.01 & 0.68 \\
\hline \multirow[t]{2}{*}{ GEM2 } & Ratio RMSE & 0.83 & 0.74 & 1.00 & 1.02 & 1.00 & 0.97 & 1.03 & 0.73 & 1.09 & 0.92 & 1.04 & 0.93 & 0.90 & 0.82 & 0.95 & 0.84 \\
\hline & DM stat. & 1.77 * & 1.93 * & 0.00 & -0.48 & 0.08 & 0.24 & -0.47 & $5.64 * \star *$ & -2.20 & 0.63 & -0.14 & 0.47 & 0.82 & 1.78 * & 0.58 & 1.80 * \\
\hline \multirow[t]{2}{*}{ GEM3 } & Ratio RMSE & 0.80 & 0.72 & 0.93 & 0.95 & 1.06 & 1.03 & 1.10 & 0.78 & 0.97 & 0.89 & 1.00 & 0.93 & 0.91 & 0.83 & 0.95 & 0.84 \\
\hline & DM stat. & 1.62 & 1.83 * & 0.62 & 0.52 & -0.86 & -0.23 & -1.41 & $3.36^{* \star *}$ & -1.27 & 0.87 & -0.15 & 0.46 & 0.75 & 1.37 & 0.52 & 1.36 \\
\hline \multirow[t]{2}{*}{ GEM4 } & Ratio RMSE & 0.80 & 0.72 & 0.93 & 0.95 & 0.99 & 0.96 & 1.07 & 0.76 & & & & & 0.90 & 0.82 & 0.91 & 0.80 \\
\hline & DM stat. & 1.59 & 1.80 * & 0.62 & 0.53 & 0.17 & 0.28 & -1.09 & 3.54 *** & & & & & 0.75 & 1.36 & 0.74 & 1.53 \\
\hline \multirow[t]{2}{*}{ GEM5 } & Ratio RMSE & 0.81 & 0.72 & 0.94 & 0.97 & 0.92 & 0.90 & 1.05 & 0.75 & & & & & 0.90 & 0.82 & 0.90 & 0.80 \\
\hline & DM stat. & 1.52 & 1.76 * & 0.46 & 0.34 & 1.46 & 0.85 & -0.71 & $3.76 * \star \star$ & & & & & 0.74 & 1.35 & 0.79 & 1.56 \\
\hline
\end{tabular}

The first row in panel A reports the RMSE of the benchmark random walk (RW) and slope-regression (SR) models. Subsequent rows show the ratio of RMSEs of model and benchmark at hand. A ratio RMSE $<1$ indicates that the model reduces forecasts errors versus the benchmark. Significance of the forecast accuracy gains is assessed with the Diebold and Mariano (1995) $t$-statistic for the null hypothesis of equal mean squared errors; $H_{0}: M S E_{\text {bench }}-M S E_{m}=0$ vs. $H_{0}: M S E_{\text {bench }}-M S E_{m} \neq 0 . *$, ** and $* * *$ is rejection at the $10 \%, 5 \%$ or $1 \%$ level, respectively. The baseline model, Eq. (4), uses the credit spread curve (level, slope and curvature) factors as predictors. Model G1 adds the U.S. yield curve factors. G2 adds the U.S. short-term interest rate volatility. GEM1 adds the country rating. GEM2 adds trade balance. GEM3 further adds volatility of trade balance. GEM4 adds terms-of-trade growth. GEM5 adds volatility of terms-of-term growth. Table 2 lists all the models. Estimation is based on weekly data and the forecast horizon is $h=13$ weeks (quarter-ahead). Bond maturity is $\tau=\{5,15\}$ years. The forecast evaluation period is July 30, 2013 to December 31 , 2015 (127 forecasts). 
On-line Addendum

\section{On the Predictability of Emerging Market Sovereign Credit Spreads}

July 30, 2018 
Panel I: Credit spreads and one-quarter lagged U.S. short-term interest rate volatility

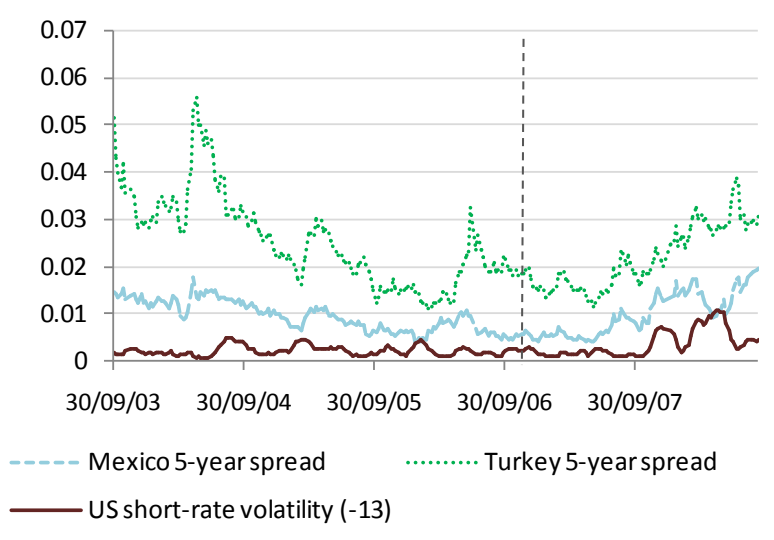

(a) Pre-Lehman

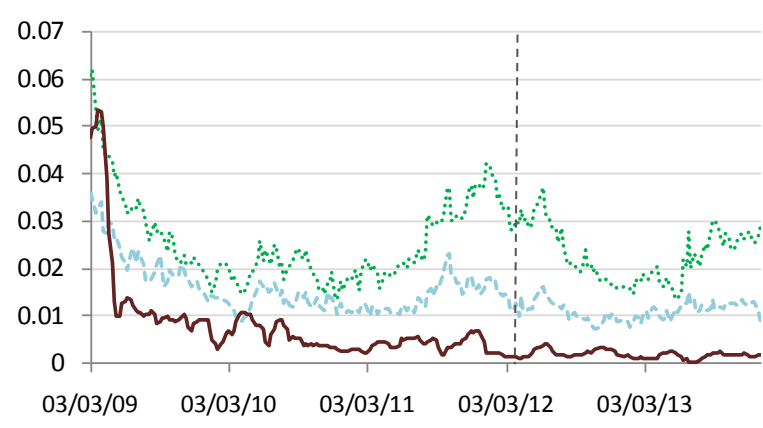

(b) Post-Lehman

Panel II: Sovereign credit spreads and one-quarter lagged trade balance volatility

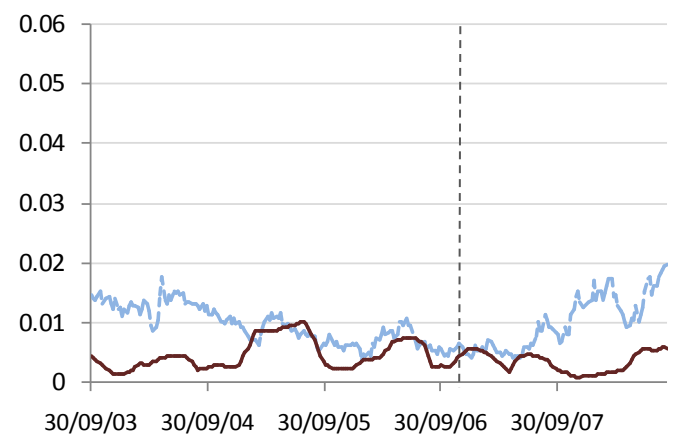

(a) Mexico: Pre-Lehman

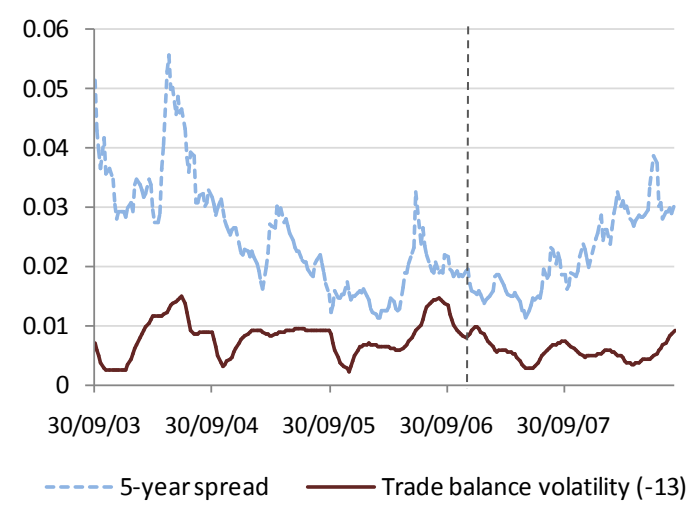

(c) Turkey: Pre-Lehman

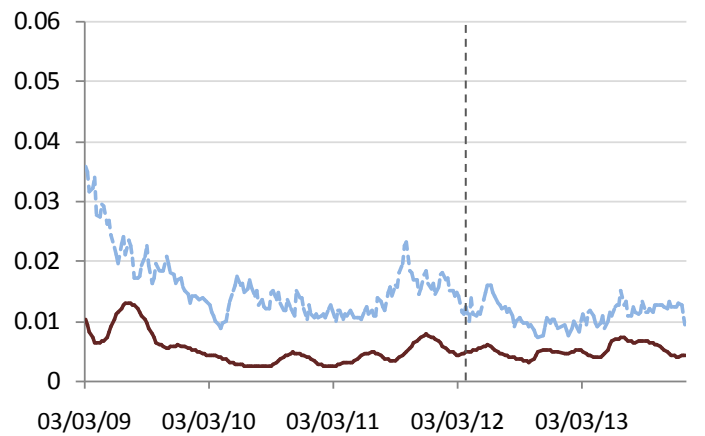

(b) Mexico: Post-Lehman

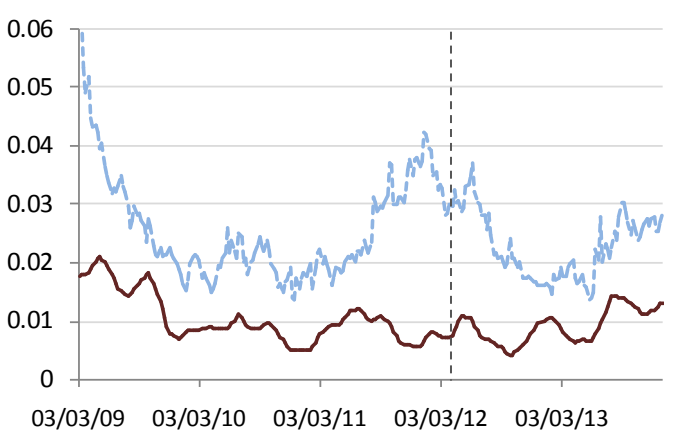

(d) Turkey: Post-Lehman

\section{FIGURE A1. CREDIT SPREADS AND LAGGED MACROECONOMIC VOLATILITY INDICATORS}

The graphs plot the 5-year credit spread of Mexico and Turkey together with the 13-week lagged U.S. short-term interest rate volatility (Panel I) and 13-week lagged country trade balance volatility (Panel II) in 5-year lengthpreLehman and post-Lehman periods. U.S. short-term interest rate (trade balance) volatility is scaled by $2.0(0.1)$ pre-Lehman and 12 (0.1) post-Lehman. The vertical line marks the start of the forecast evaluation period. The sampling frequency is weekly from July 1, 2003 to December 31, 2013. 
TABLE A1

Summary Statistics of Credit SPREAds and Predictive VARIABles: Post-LeHMAN ExTENDEd

\begin{tabular}{|c|c|c|c|c|c|c|c|c|c|c|c|}
\hline $\begin{array}{c}\text { Country } \\
\text { Variable }\end{array}$ & Mean & StDev & Min & Max & $A R(1)$ & $\begin{array}{c}\text { Country } \\
\text { Variable }\end{array}$ & Mean & StDev & Min & Max & $\operatorname{AR}(1)$ \\
\hline \multicolumn{12}{|l|}{ US } \\
\hline$\beta_{f, 0}$ & 0.043 & 0.008 & 0.027 & 0.058 & 0.986 & & & & & & \\
\hline$\beta_{f, 1}$ & -0.028 & 0.013 & -0.053 & -0.004 & 0.981 & & & & & & \\
\hline$\beta_{f, 2}$ & -0.079 & 0.025 & -0.139 & -0.022 & 0.978 & & & & & & \\
\hline$\sigma_{f}^{\text {short }}$ & 0.000 & 0.001 & 0.000 & 0.004 & 0.977 & & & & & & \\
\hline Brazil & & & & & & Philippines & & & & & \\
\hline$s(5)$ & 0.016 & 0.008 & 0.004 & 0.050 & 0.973 & $s(5)$ & 0.016 & 0.010 & 0.005 & 0.067 & 0.989 \\
\hline$s(15)$ & 0.022 & 0.009 & 0.010 & 0.056 & 0.976 & $s(15)$ & 0.019 & 0.008 & 0.008 & 0.051 & 0.977 \\
\hline$\beta_{0}$ & 0.025 & 0.010 & 0.012 & 0.061 & 0.974 & $\beta_{0}$ & 0.021 & 0.007 & 0.008 & 0.042 & 0.954 \\
\hline$\beta_{1}$ & -0.011 & 0.020 & -0.061 & 0.062 & 0.887 & $\beta_{1}$ & -0.008 & 0.017 & -0.042 & 0.080 & 0.913 \\
\hline$\beta_{2}$ & -0.025 & 0.040 & -0.154 & 0.069 & 0.925 & $\beta_{2}$ & -0.009 & 0.039 & -0.151 & 0.159 & 0.945 \\
\hline$C R$ & 39.196 & 3.146 & 32.500 & 45.500 & 0.978 & $C R$ & 43.157 & 2.267 & 36.000 & 46.500 & 0.991 \\
\hline$T B$ & 0.067 & 0.081 & -0.159 & 0.379 & 0.978 & $T B$ & -0.258 & 0.184 & -0.595 & 0.293 & 0.976 \\
\hline$\sigma_{T B}$ & 0.054 & 0.027 & 0.021 & 0.157 & 0.990 & $\sigma_{T B}$ & 0.154 & 0.060 & 0.077 & 0.337 & 0.988 \\
\hline$\Delta \pi$ & 0.052 & 8.790 & -13.276 & 19.361 & 0.997 & & & & & & \\
\hline$\sigma_{\Delta \pi}$ & 2.747 & 1.560 & 0.389 & 8.899 & 0.991 & & & & & & \\
\hline Mexico & & & & & & Turkey & & & & & \\
\hline$s(5)$ & 0.014 & 0.006 & 0.006 & 0.047 & 0.972 & $s(5)$ & 0.025 & 0.009 & 0.013 & 0.073 & 0.964 \\
\hline$s(15)$ & 0.019 & 0.006 & 0.011 & 0.045 & 0.950 & $s(15)$ & 0.027 & 0.008 & 0.014 & 0.062 & 0.967 \\
\hline$\beta_{0}$ & 0.021 & 0.006 & 0.013 & 0.044 & 0.930 & $\beta_{0}$ & 0.029 & 0.008 & 0.013 & 0.063 & 0.961 \\
\hline$\beta_{1}$ & -0.009 & 0.014 & -0.044 & 0.024 & 0.874 & $\beta_{1}$ & -0.007 & 0.017 & -0.055 & 0.061 & 0.797 \\
\hline$\beta_{2}$ & -0.021 & 0.032 & -0.086 & 0.063 & 0.930 & $\beta_{2}$ & -0.006 & 0.030 & -0.124 & 0.127 & 0.796 \\
\hline$C R$ & 40.289 & 1.908 & 35.500 & 43.000 & 0.978 & $C R$ & 33.740 & 2.550 & 27.000 & 37.500 & 0.981 \\
\hline$T B$ & -0.033 & 0.071 & -0.272 & 0.085 & 0.958 & $T B$ & -0.816 & 0.227 & -1.253 & -0.202 & 0.993 \\
\hline$\sigma_{T B}$ & 0.066 & 0.032 & 0.024 & 0.135 & 0.992 & $\sigma_{T B}$ & 0.110 & 0.041 & 0.042 & 0.209 & 0.989 \\
\hline$\Delta \pi$ & -2.778 & 9.850 & -22.243 & 19.394 & 0.998 & $\Delta \pi$ & 0.857 & 4.350 & -8.864 & 9.667 & 0.995 \\
\hline$\sigma_{\Delta \pi}$ & 3.609 & 2.973 & 0.356 & 14.099 & 0.994 & $\sigma_{\Delta \pi}$ & 1.732 & 1.183 & 0.241 & 5.320 & 0.993 \\
\hline
\end{tabular}

The table reports mean, standard deviation, minimum, maximum and 1st-order autocorrelation of 5- and 15-year bond spreads, and candidate predictors used in hierarchical regressions. Table 2 lists all the models. The betas are level, slope and curvature of the U.S. yield curve (US) and credit spread curve (Brazil, Mexico, Philippines and Turkey) extracted from cross-sections of bond prices sampled at the weekly frequency. $\sigma_{f}^{\text {short }}$ is the standard deviation of the U.S. short-term interest rate over the most recent 10 -week period.CR is country risk. TB is trade balance. $\triangle T T$ is year-on-year terms of trade growth. $\sigma_{T B}\left(\sigma_{\triangle T T}\right)$ is the standard deviation of $T B(\Delta T T)$ over the most recent 6-month period. The extended post-Lehman period is December 1, 2008 to December 31, 2015 (367 weeks). 


\section{TABLE A2}

Benchmarking the Predictive Models During the Extended Post-Lehman Period

\begin{tabular}{|c|c|c|c|c|c|c|c|c|c|c|c|c|c|c|c|c|c|}
\hline \multirow[b]{3}{*}{ Model } & & \multicolumn{4}{|c|}{ Brazil } & \multicolumn{4}{|c|}{ Mexico } & \multicolumn{4}{|c|}{ Philippines } & \multicolumn{4}{|c|}{ Turkey } \\
\hline & & \multicolumn{2}{|c|}{ 5-year spread } & \multicolumn{2}{|c|}{ 15-year spread } & \multicolumn{2}{|c|}{ 5-year spread } & \multicolumn{2}{|c|}{ 15-year spread } & \multicolumn{2}{|c|}{ 5-year spread } & \multicolumn{2}{|c|}{ 15-year spread } & \multicolumn{2}{|c|}{ 5-year spread } & \multicolumn{2}{|c|}{ 15-year spread } \\
\hline & & RW & SR & RW & SR & RW & $S R$ & RW & SR & RW & SR & RW & SR & RW & $\mathrm{SR}$ & RW & SR \\
\hline & \multicolumn{17}{|c|}{ Panel A: Baseline and global variables } \\
\hline Benchmark & RMSE & 63.0 & 70.4 & 61.9 & 60.6 & 22.5 & 23.1 & 26.3 & 37.0 & 20.4 & 26.6 & 25.5 & 27.9 & 50.4 & 55.2 & 46.3 & 52.2 \\
\hline \multirow[t]{2}{*}{ Baseline } & Ratio RMSE & 0.91 & 0.81 & 1.02 & 1.04 & 0.89 & 0.87 & 1.07 & 0.76 & 1.10 & 0.84 & 0.91 & 0.83 & 0.84 & 0.77 & 0.95 & 0.84 \\
\hline & DM stat. & 2.42 ** & 2.52 ** & -0.56 & -1.06 & $2.77 * \star \star$ & 1.34 & -0.92 & 5.95 *** & -1.28 & 1.09 & 0.80 & 1.01 & 1.94 * & 3.51 *** & 0.64 & 2.41 ** \\
\hline \multirow[t]{3}{*}{ G2 } & Ratio RMSE & 0.88 & 0.78 & 1.00 & 1.02 & 0.92 & 0.90 & 0.99 & 0.71 & 1.06 & 0.82 & 1.04 & 0.95 & 0.79 & 0.72 & 0.87 & 0.77 \\
\hline & DM stat. & 2.11 ** & 2.23 ** & 0.08 & -0.38 & 1.61 & 0.98 & 0.16 & $5.57^{* \star \star}$ & -0.84 & 1.29 & -0.27 & 0.30 & 2.63 ** & $3.93 * \star \star$ & 1.72 * & $3.59 * \star *$ \\
\hline & \multicolumn{17}{|c|}{ Panel B: Domestic variables } \\
\hline \multirow[t]{2}{*}{ GEM1 } & Ratio RMSE & 0.87 & 0.78 & 1.00 & 1.02 & 0.91 & 0.88 & 1.00 & 0.71 & 0.98 & 0.75 & 0.93 & 0.85 & 0.84 & 0.77 & 0.92 & 0.81 \\
\hline & DM stat. & 2.18 ** & 2.28 ** & 0.10 & -0.36 & 1.76 * & 1.14 & -0.02 & 5.96 *** & 0.31 & 1.88 * & 0.50 & 0.82 & 2.12 ** & $3.81 * \star \star$ & 1.13 & $3.73^{* * *}$ \\
\hline \multirow[t]{2}{*}{ GEM2 } & Ratio RMSE & 0.79 & 0.71 & 0.97 & 0.99 & 0.92 & 0.90 & 0.97 & 0.69 & 1.08 & 0.83 & 0.97 & 0.88 & 0.81 & 0.74 & 0.96 & 0.85 \\
\hline & DM stat. & 2.24 ** & 2.24 ** & 0.49 & 0.18 & 1.40 & 0.95 & 0.51 & 5.76 *** & -0.83 & 1.27 & 0.24 & 0.64 & 1.43 & 2.55 ** & 0.35 & 1.54 \\
\hline \multirow[t]{2}{*}{ GEM3 } & Ratio RMSE & 0.77 & 0.69 & 0.90 & 0.92 & 0.96 & 0.93 & 1.04 & 0.74 & 0.97 & 0.74 & 1.02 & 0.93 & 0.78 & 0.71 & 0.90 & 0.80 \\
\hline & DM stat. & 1.86 * & 1.99 ** & 0.90 & 0.86 & 0.52 & 0.51 & -0.59 & 4.02 *** & 0.39 & 2.08 ** & -0.15 & 0.36 & 1.66 * & 2.49 ** & 0.84 & $1.87^{*}$ \\
\hline \multirow[t]{2}{*}{ GEM4 } & Ratio RMSE & 0.77 & 0.69 & 0.88 & 0.90 & 0.93 & 0.91 & 1.04 & 0.74 & & & & & 0.76 & 0.70 & 0.82 & 0.73 \\
\hline & DM stat. & 1.86 * & 1.99 ** & 1.04 & 1.02 & 0.85 & 0.73 & -0.62 & 3.86 *** & & & & & 1.77 * & $2.58 * *$ & 1.47 & 2.35 ** \\
\hline \multirow[t]{2}{*}{ GEM5 } & Ratio RMSE & 0.76 & 0.68 & 0.88 & 0.90 & 0.89 & 0.87 & 1.01 & 0.72 & & & & & 0.78 & 0.71 & 0.79 & 0.70 \\
\hline & DM stat. & 1.81 * & 1.95 * & 0.98 & 0.94 & 1.65 & 1.04 & -0.21 & $4.36^{* \star *}$ & & & & & 1.69 * & 2.37 ** & 1.70 * & 2.43 ** \\
\hline
\end{tabular}

The first row in Panel A reports the RMSE of the benchmark random walk (RW) and slope-regression (SR) predictive models. Subsequent rows report the ratio of RMSEs of the model at hand to the benchmark. A ratio RMSE $<1$ indicates that the model brings a forecast error reduction versus the benchmark. Significance of the forecast accuracy gains is assessed with the Diebold and Mariano (1995) $t$-statistic for the null hypothesis of equal mean squared error; $H_{0}: M S E_{b e n c h}-M S E_{m}=$ 0 vs. $H_{A}: M S E_{\text {bench }}-M S E_{m} \neq 0 . *, * *$ and $* * *$ denote rejection at the $10 \%, 5 \%$ or $1 \%$ level, respectively. The baseline model, Eq. (4), exploits the credit spread curve factors. The models $G 2$ to GEM5 are those used in the previous analysis (as listed in Table 2) but without the U.S. yield curve factors as predictors. Estimation is based on weekly data and the forecast horizon is $h=13$ weeks (quarter-ahead). Bond maturity is $\tau=\{5,15\}$ years. The forecast evaluation period is July 30 , 2013 to December 31, 2015 (127 forecasts). 